\title{
Dysregulation of voltage-gated sodium channels by ubiquitin ligase NEDD4-2 in neuropathic pain
}

\author{
Cédric J. Laedermann, ${ }^{1,2}$ Matthieu Cachemaille, ${ }^{1}$ Guylène Kirschmann, ${ }^{1}$ Marie Pertin, ${ }^{1}$ \\ Romain-Daniel Gosselin, ${ }^{1}$ Isabelle Chang, ${ }^{1}$ Maxime Albesa, ${ }^{2}$ Chris Towne, ${ }^{3}$ \\ Bernard L. Schneider, ${ }^{3}$ Stephan Kellenberger, ${ }^{4}$ Hugues Abriel, ${ }^{2}$ and Isabelle Decosterd ${ }^{1,5}$ \\ ${ }^{1}$ Pain Center, Department of Anesthesiology, University Hospital Center (CHUV) and University of Lausanne, Lausanne, Switzerland. \\ 2Department of Clinical Research, University of Bern, Bern, Switzerland. ${ }^{3}$ Brain Mind Institute, Ecole Polytechnique Fédérale de Lausanne (EPFL), \\ Lausanne, Switzerland. ${ }^{4}$ Department of Pharmacology and Toxicology and ${ }^{5}$ Department of Fundamental Neurosciences, \\ University of Lausanne, Lausanne, Switzerland.
}

\begin{abstract}
Peripheral neuropathic pain is a disabling condition resulting from nerve injury. It is characterized by the dysregulation of voltage-gated sodium channels $\left(\mathrm{Na}_{v} \mathrm{~s}\right)$ expressed in dorsal root ganglion (DRG) sensory neurons. The mechanisms underlying the altered expression of $\mathrm{Na}_{\mathrm{v}} \mathrm{s}$ remain unknown. This study investigated the role of the $\mathrm{E} 3$ ubiquitin ligase NEDD4-2, which is known to ubiquitylate $\mathrm{Na}_{\mathrm{v}} \mathrm{s}$, in the pathogenesis of neuropathic pain in mice. The spared nerve injury (SNI) model of traumatic nerve injury-induced neuropathic pain was used, and an $\mathrm{Na}_{\mathrm{v}} 1.7$-specific inhibitor, ProTxII, allowed the isolation of $\mathrm{Na}_{\mathrm{v}} 1.7$-mediated currents. SNI decreased NEDD4-2 expression in DRG cells and increased the amplitude of $\mathrm{Na}_{\mathrm{v}} 1.7$ and $\mathrm{Na}_{\mathrm{v}} 1.8$ currents. The redistribution of $\mathrm{Na}_{\mathrm{v}} 1.7$ channels toward peripheral axons was also observed. Similar changes were observed in the nociceptive DRG neurons of Nedd4L knockout mice (SNS-Nedd4L $\mathrm{L}^{-/-}$). SNS-Nedd4L $\mathrm{L}^{-/-}$mice exhibited thermal hypersensitivity and an enhanced second pain phase after formalin injection. Restoration of NEDD4-2 expression in DRG neurons using recombinant adenoassociated virus (rAAV2/6) not only reduced $\mathrm{Na}_{\mathrm{v}} 1.7$ and $\mathrm{Na}_{v} 1.8$ current amplitudes, but also alleviated SNI-induced mechanical allodynia. These findings demonstrate that NEDD4-2 is a potent posttranslational regulator of $\mathrm{Na}_{v} \mathrm{~s}$ and that downregulation of NEDD4-2 leads to the hyperexcitability of DRG neurons and contributes to the genesis of pathological pain.
\end{abstract}

\section{Introduction}

Neuropathic pain is a direct consequence of alterations in the somatosensory system. It affects approximately $7 \%$ of the general population and is insufficiently treated with currently available drugs (1). Following nerve injury, there is ectopic spontaneous activity of afferent neurons due to the increased expression of voltage-gated sodium channels $\left(\mathrm{Na}_{v} \mathrm{~s}\right)(2,3)$. This hyperexcitability mediates enduring changes in the nervous system, contributing to both peripheral and central sensitization (4). $\mathrm{Na}_{v} \mathrm{~S}$ are heteromeric glycosylated protein complexes composed of a large pore-forming $\alpha$ subunit and auxiliary $\beta$ subunits $(5,6)$. Nine genes encode for distinct channel isoforms $\left(\mathrm{Na}_{\mathrm{v}} 1.1\right.$ to $\left.\mathrm{Na}_{\mathrm{v}} 1.9\right)$, each displaying specific properties. They are classified according to their sensitivity to tetrodotoxin (TTX). All isoforms, except $\mathrm{Na}_{v} 1.4$ and $\mathrm{Na}_{\mathrm{v}} 1.5$, are expressed in the dorsal root ganglia (DRG) and trigeminal ganglia (TG) nociceptive neurons, with $\mathrm{Na}_{v} 1.8$ and $\mathrm{Na}_{v} 1.9$ being expressed almost exclusively in DRG/ TG neurons and $\mathrm{Na}_{\mathrm{v}} 1.7$ in DRG/TG and sympathetic ganglion neurons (7). $\mathrm{Na}_{\mathrm{v}} 1.7$ is expressed at higher levels in DRG/TG than are other TTX-sensitive isoforms $(7,8)$ and plays an essential role in the modulation of human pain perception. Naturally occurring mutations in $S C N 9 A$, the gene encoding $\mathrm{Na}_{\mathrm{v}} 1.7$, lead to either congenital insensitivity or severe episodic hypersen-

Authorship note: Hugues Abriel and Isabelle Decosterd contributed equally to this work.

Conflict of interest: The authors have declared that no conflict of interest exists. Citation for this article: J Clin Invest. 2013;123(7):3002-3013. doi:10.1172/JCI68996 sitivity to pain (9-11). In addition, $\mathrm{Na}_{\mathrm{v}} 1.7$ and $\mathrm{Na}_{\mathrm{v}} 1.8$ gain-offunction mutations in painful peripheral neuropathy syndromes were recently described $(12,13)$. Not only are $\mathrm{Na}_{v} 1.7$ and $\mathrm{Na}_{v} 1.8$ important in inherited pain disorders, but also in acquired pain disorders, where their increased expression has already been linked to diverse chronic pain symptoms (14-16). Studies using knockout mice have implicated $\mathrm{Na}_{v} 1.7$ and $\mathrm{Na}_{v} 1.8$ in acute and inflammatory pain (17-20), but their involvement in hyperexcitability and neuropathic pain remains to be determined.

The control of $\mathrm{Na}_{\mathrm{v}}$ density at the cell membrane is crucial to ensuring normal neuronal excitability. Despite extensive research on the subject, the regulation of $\mathrm{Na}_{v}$ s in neuropathic pain remains poorly understood. $\mathrm{Na}_{v} \mathrm{~S}$ are subject to posttranslational modifications that may influence their cell membrane availability. Ubiquitylation is a key process that orchestrates the internalization and subsequent degradation or recycling of $\mathrm{Na}_{v} \mathrm{~s}$ (21). The final and limiting step is the covalent attachment of ubiquitin moieties to lysine residues of the target protein. This is accomplished by ubiquitin protein ligases, such as NEDD4-2 (neuronal precursor cell expressed developmentally downregulated-4 type 2). NEDD4-2 is a member of the NEDD4/NEDD4-like E3 subfamily of ubiquitin ligases, whose type I WWW domains interact with the PY motifs (PPxY) of target proteins. All $\mathrm{Na}_{v}$ isoforms, except $\mathrm{Na}_{v} 1.4$ and $\mathrm{Na}_{v} 1.9$, possess a PY motif and are potential targets of NEDD4-2. In vitro experiments have indicated that NEDD4-2 can negatively regulate the epithelial sodium channel $\mathrm{ENaC}(22)$ and $\mathrm{Na}_{v} \mathrm{~s}(23,24)$. The functional relevance of NEDD4-2 in sensory neurons, as well as its possible involvement in pain sensitivity, have yet to be investigated. 

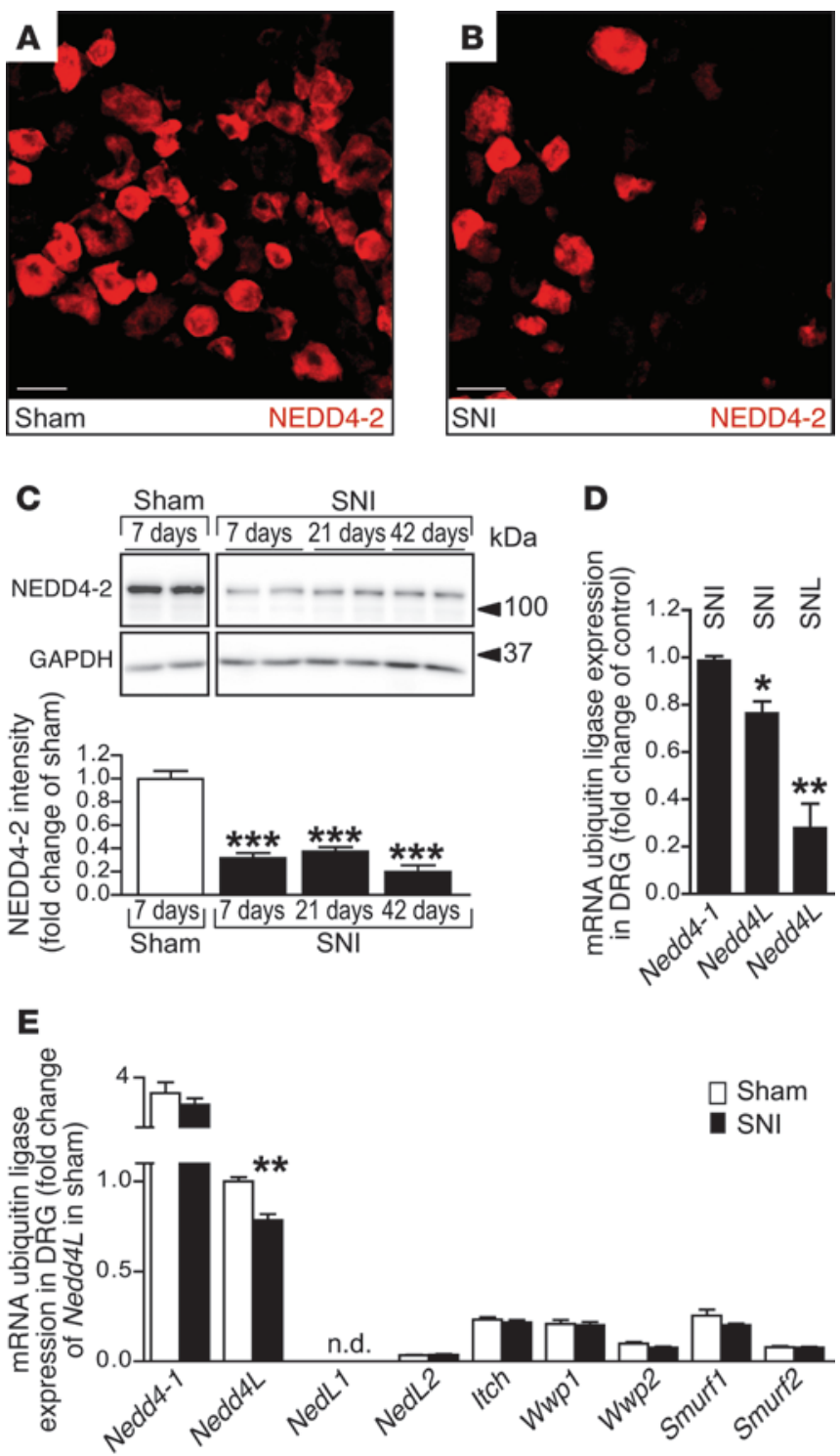

NEDD4-2 was recently shown to be decreased in rat DRG in the spared nerve injury (SNI) model of traumatic nerve injuryinduced neuropathic pain (25). The present study postulated that reduced levels of NEDD4-2 jeopardize the correct addressing or anchoring of $\mathrm{Na}_{\mathrm{v}} \mathrm{s}$ in DRG nociceptive neurons. NEDD4-2 expression was controlled in cellular expression systems and in mice with DRG-specific gene deletions or rAAV-mediated gene transfers. This enabled the selective investigation of the effect of NEDD4-2 on $\mathrm{Na}_{v} 1.7$ and $\mathrm{Na}_{v} 1.8$ currents, as well its impacts on pain sensitivity. The results provide what we believe to be the first in vivo mechanistic evidence that NEDD4-2 enables the fine-tuning of neuronal excitability in DRG cells. Furthermore, these results may demonstrate that the pathological reduction of NEDD4-2 underlies traumatic nerve injury-induced neuropathic pain.

\section{Results}

Peripheral nerve injury reduces NEDD4-2 expression in DRG. The protein and mRNA levels of Nedd $4 L$ were measured to explore whether $N e d d 4 L$ is regulated after nerve injury in mice and whether it contrib-

\section{Figure 1}

Peripheral nerve injury reduces NEDD4-2 expression in DRG. (A and B) Immunofluorescence of NEDD4-2 in coronal sections of L4 DRG from sham-operated and SNI mice. Scale bars: $30 \mu \mathrm{m}$. (C) Representative Western blot analysis showing the decrease in NEDD4-2 at days 7, 21, and 42 after SNI in L4/5 DRG and its associated quantification. Data are expressed as the means \pm SEM; $n=4$ samples for each time point per group. ${ }^{* * *} P<0.001$ by 1 -way ANOVA with Bonferroni's post-hoc test. GAPDH was used as a loading control. Lanes were run on the same gel but were noncontiguous. (D) Effect of SNI and SNL on Nedd4-1 and Nedd4L transcripts in L4/5 DRG 7 days after SNI or SNL (injury of L5 spinal nerve). Bar graph showing transcriptional levels of Nedd4-1 and Nedd $4 L$ normalized to GAPDH in SNI and SNL groups over the control group (sham for SNI and L4 DRG for SNL). Data represent the mean $\pm \mathrm{SEM} ; n=4$ samples per group. Isolated L4/5, L5, or L4 DRG from 2 mice were pooled for each sample and run in triplicate. ${ }^{\star} P=0.011,{ }^{* *} P=0.004$, Student's $t$ test. (E) Constitutive transcript levels of Nedd4/Nedd4-like E3 subfamily members in L4/5 DRG 7 days after sham and SNI surgery. Transcript levels were normalized using HPRT as a reference gene and further normalized to $N e d d 4 L$ levels in sham-operated mice. Data are expressed as the means \pm SEM; $n=3-4$ samples per group, which were run in triplicate. ${ }^{\star \star} P=0.005$, Student's $t$ test. We detected no amplification of NedL1 in the DRG samples. utes to phenotypic changes in DRG neurons. A substantial decrease of NEDD4-2 expression was observed by immunofluorescence in lumbar L4/L5 DRG 7 days after SNI (Figure 1, A and B). This decrease was further quantified using Western blot analysis. SNI decreased NEDD4-2 protein levels by greater tha $60 \%$ in DRG, an effect that lasted for at least 6 weeks (Figure 1C). Both SNI and spinal nerve ligation (SNL) reduced Nedd4L transcript levels (Figure 1D). Nedd4L mRNA was abundantly expressed in lumbar L4/5 DRG and was the only member of the Nedd4/Nedd4-like E3 subfamily to be downregulated after SNI (Figure 1E).

NEDD4-2 interacts with, ubiquitylates, and downregulates $\mathrm{Na}_{v} 1.7$ in HEK293 cells. Since $\mathrm{Na}_{v} 1.7$ is essential for pain sensation, NEDD42 downregulation of $\mathrm{Na}_{v} 1.7$ in mammalian cells was investigated, as previously reported in Xenopus oocytes (24). Whole-cell $\mathrm{Na}^{+}$ currents $\left(I_{\mathrm{Na}}\right)$ were recorded in HEK293 cells cotransfected with $\mathrm{Na}_{\mathrm{v}} 1.7$ and NEDD4-2. NEDD4-2 decreased $\mathrm{Na}_{\mathrm{v}} 1.7$ current density by approximately $80 \%$ (Figure 2 , A and B). The biophysical properties of $\mathrm{Na}_{\mathrm{v}} 1.7$ were unaffected by NEDD4-2 (Supplemental Table 1 and Supplemental Figure 1A; supplemental material 
A
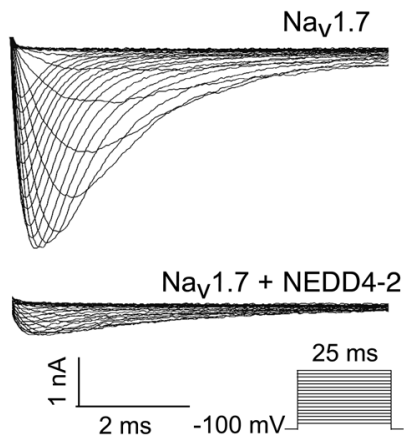

B

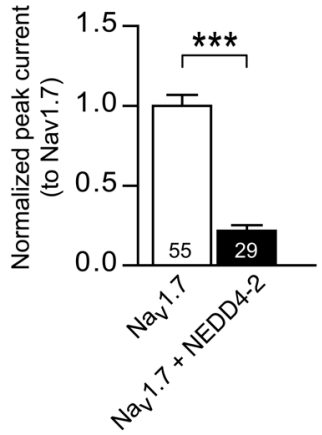

C
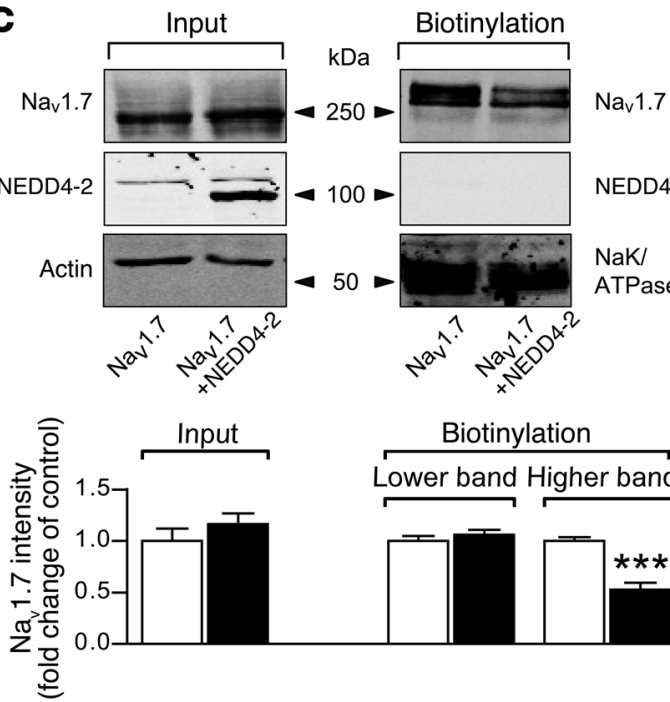

NEDD4-2

NaK/

ATPase (ß)

D

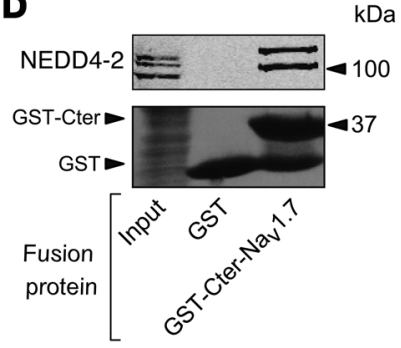

Biotinylation
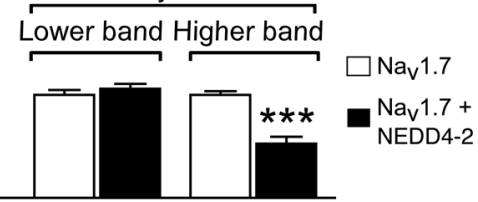

$\mathbf{E}$

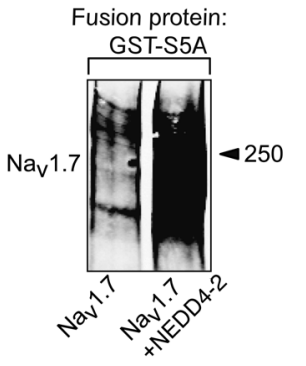

available online with this article; doi:10.1172/JCI68996DS1), suggesting that NEDD4-2 mainly reduces the number of channels at the cell surface. Cell-surface proteins were then biotinylated and precipitated. Upon NEDD4-2 cotransfection, expression of the fully glycosylated form of $\mathrm{Na}_{v} 1.7$ (Supplemental Figure 1B) was decreased by approximately $50 \%$ in the plasma membrane fraction, but remained unchanged in the total lysate (Figure 2C, see also Supplemental Figure 1, C and D, for additional in vitro experiments). The interaction between $\mathrm{Na}_{v} 1.7$ and NEDD4-2 was examined by pull-down experiments using GST fused to the furthest $66 \mathrm{C}$-terminal amino acid residues of $\mathrm{Na}_{\mathrm{v}} 1.7$, which include the PY motif (GST-Cter- $\mathrm{Na}_{v} 1.7$ ). $\mathrm{Na}_{v} 1.7$ GST fusion proteins interacted with endogenous and transfected NEDD4-2, whereas GST alone did not (Figure 2D). Finally, whether $\mathrm{Na}_{\mathrm{v}} 1.7$ could be a substrate of NEDD4-2 ubiquitylating activity was tested by pulling down ubiquitylated proteins using GST fused to the

\section{Figure 2}

NEDD4-2 downregulates membrane $\mathrm{Na}_{v}$ 1.7. (A) Representative current traces obtained with a V-I protocol (see Methods) on HEK293 cells after $\mathrm{Na}_{v} 1.7$ transfection or cotransfection with NEDD4-2. (B) Quantification of current densities from A. NEDD4-2 reduced $\mathrm{Na}_{\mathrm{v}} 1.7$ current density $\left.{ }^{* * *} P<0.001\right)$. See Supplemental Figure $1 \mathrm{~A}$ and Supplemental Table 1 for values and biophysical properties. (C) Surface biotinylation of HEK293 cells and their associated quantification. In membrane fractions, NEDD4-2 reduced the fully glycosylated form of $\left.\mathrm{Na}_{v} 1.7{ }^{* * \star} P<0.001\right)$, whereas the core glycosylated form remained unchanged $(P=0.416)$. $\mathrm{Na}_{\mathrm{v}} 1.7$ total expression was unchanged ( $P=0.337$; Input). The $\beta 1$ subunit of the NaK/ATPase and actin were used as loading controls in input and biotinylation fractions, respectively. Deglycosylation experiments are presented in Supplemental Figure 1B. NEDD4-2 antibody recognizes both endogenous $(120 \mathrm{kDa})$ and transfected $(100 \mathrm{kDa})$ proteins. (D) GST pull-down experiment showing $\mathrm{Na}_{\mathrm{v}} 1.7 \mathrm{PY}$ motif interaction with NEDD4-2. HEK293 cells were transfected with NEDD4-2, and soluble fractions were mixed GST proteins or GST-Cter-Na 1.7 fusion proteins. Bound NEDD4-2 was analyzed by Western blot. The entire Western blot with PY motif mutants can be seen in Supplemental Figure 2E. (E) NEDD4-2-mediated ubiquitylation. HEK293 cells were transfected with $\mathrm{Na}_{v} 1.7$ or cotransfected with NEDD4-2, and soluble fractions were mixed with GST-S5A proteins to pull down ubiquitylated proteins. Bound $\mathrm{Na}_{\mathrm{v}} 1.7$ was analyzed by Western blotting. The entire Western blot with PY motif mutants can be seen in Supplemental Figure 2F. 
A

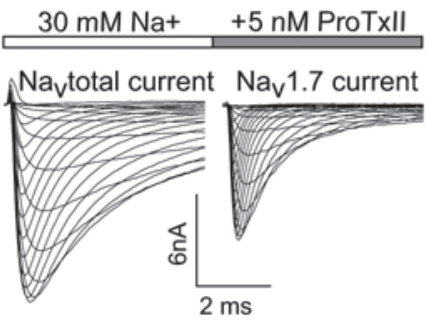

$+300 \mu \mathrm{M}$ TTX

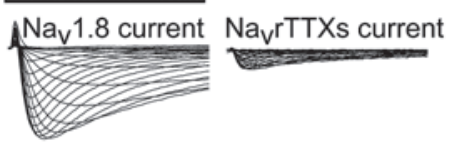

D
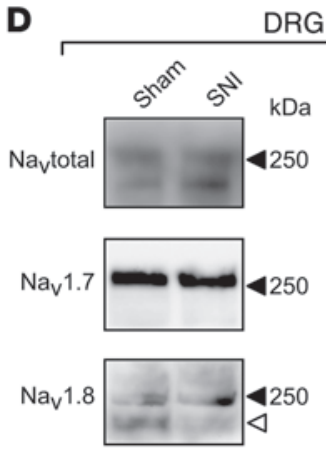

Tubulin

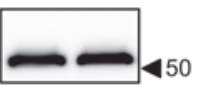

B

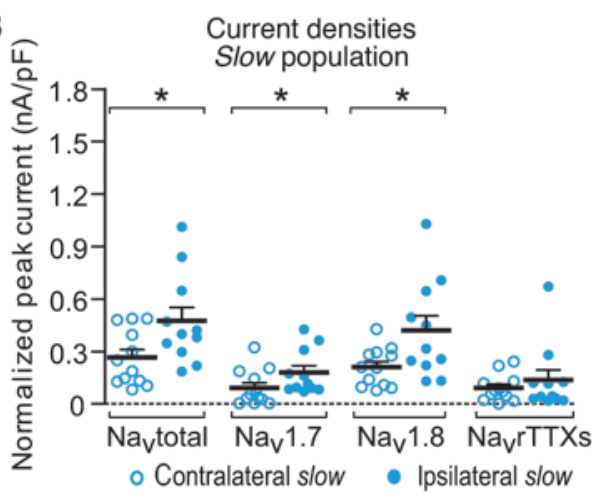

\section{C}

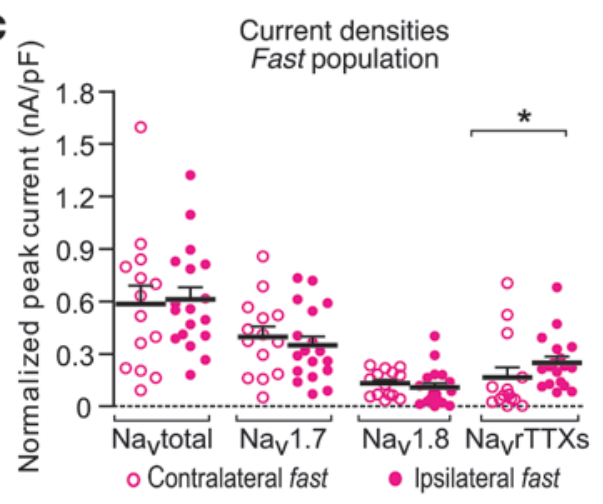

\section{Figure 3}

Increase in $\mathrm{Na}_{v} 1.7$ and $\mathrm{Na}_{v} 1.8$ currents in DRG neurons and increased expression of $\mathrm{Na}_{v} 1.7$ along the sciatic nerve after SNI. (A) Typical recordings of $I_{\mathrm{Na}}$ in DRG neurons using the V-I protocol and pharmacological isolation of $\mathrm{Na}_{\mathrm{v}}$ total, $\mathrm{Na}_{\mathrm{v}} 1.7, \mathrm{Na}_{\mathrm{v}} 1.8$, and $\mathrm{Na}_{\mathrm{v}} \mathrm{rTTX}$. currents with ProTxll and TTX (see Methods). (B and C) Scatter dot plot representing Na $a_{v}$ total, $\mathrm{Na}_{v} 1.7, \mathrm{Na}_{v} 1.8$, and NavrTTXs current densities in contralateral and ipsilateral sides recorded in L4/5 DRG neurons 1 week after SNI. Slow (B, in cyan) and fast (C, in magenta) neurons are shown. Mann-Whitney $U$ test. See Supplemental Figure 3A for the total population and see Supplemental Table 2 for values and biophysical properties. (D) Left panel: representative Western blot analysis and quantification of $\mathrm{Na}_{v} \alpha$ subunits: $\mathrm{Na}_{v}$ total, $\mathrm{Na}_{v} 1.7$, and $_{\mathrm{Na}} 1.8$ in DRG 7 days after SNI. No modifications in $\mathrm{Na}_{\mathrm{v}}$ total $(P=0.496)$, Nav1.7 $(P=0.690)$, or $\mathrm{Na}_{\mathrm{v}} 1.8(P=0.311)$ were observed in sham- and SNI-operated mice. Right panel: same as above, but for sciatic nerve preparation. Na $1.7\left({ }^{*} P=0.045\right)$ and $\mathrm{Na}_{\mathrm{v}}$ total $\left({ }^{\star} P=0.021\right)$ were significantly increased in SNI compared with the sham samples. The $\mathrm{Na}_{\mathrm{v}} 1.8$ signal in the SNI sample did not reach significance compared with the background signal in the sham-operated group $(P=0.105)$ (see Supplemental Figure 3B). The 2 open arrowheads correspond to a distinct band of $\mathrm{Na}_{\mathrm{v}} 1.8$, with lower molecular weight than the band observed at $250 \mathrm{kDa}$. Data are expressed as the means $\pm \mathrm{SEM} ; n=4$ samples for each group. Student's $t$ test. Tubulin was used as a loading control. Int., intensity.

ing TTX-sensitive currents $\left(\mathrm{Na}_{\mathrm{v}} 1.1, \mathrm{Na}_{\mathrm{v}} 1.2, \mathrm{Na}_{\mathrm{v}} 1.3\right.$, and $\mathrm{Na}_{\mathrm{v}} 1.6$ currents collectively referred to as $\mathrm{Na}_{\mathrm{v}} \mathrm{rTTX}$ ), and the TTX-resistant currents (referred to as $\mathrm{Na}_{v} 1.8$, since $\mathrm{Na}_{v} 1.9$ was inactivated by an ad-hoc electrophysiological protocol; see Methods) (Figure $3 \mathrm{~A})$. Recorded cells were small neurons $(<30 \mathrm{pF})$, considered to be nociceptive neurons (27). Despite the fact that the distinction between intact or severed neurons was not made, a significant increase in the $\mathrm{Na}_{\mathrm{v}}$ total $(P=0.013)$ and $\mathrm{Na}_{\mathrm{v}} \mathrm{rTTXs}(P=0.021)$ current densities after SNI were measured (ipsilateral compared with the contralateral side, Supplemental Figure 3A). Since the expression of $\mathrm{Na}_{\mathrm{v}} \mathrm{S}$ in DRG is heterogeneous, the analysis was refined by segregating cells into fast and slow neurons, as previously reported (27). A neuron was characterized as slow when the $I_{\mathrm{Na}}$ density ratio of the $\mathrm{Na}_{\mathrm{v}} 1.8 / \mathrm{Na}_{\mathrm{v}}$ total was greater than 0.5 , with $\mathrm{Na}_{\mathrm{v}} 1.8$ displaying slower inactivation kinetics. Conversely, when this ratio was less than 0.5 , the neuron was defined as fast (27). This selection revealed that SNI significantly increased $\mathrm{Na}_{\mathrm{v}} 1.7$ and $\mathrm{Na}_{v} 1.8$ current densities in the slow subpopulation only (Figure $3 \mathrm{~B}$ ). The fast subpopulation showed a small but significant increase in $\mathrm{Na}_{\mathrm{v}} \mathrm{rTTX}$ alone (Figure 3C; $P=0.014$ ).

SNI had only a minor impact on the biophysical properties (voltage dependence of steady-state activation and inactivation) of some of the $\mathrm{Na}_{v}$ components (Supplemental Table 2). In line with previous studies $(28,29)$, nerve injury induced an acceleration of the recovery from inactivation (repriming) for every component of $I_{\mathrm{Na}}$ of the fast subpopulation (Supplemental Table 2).

Western blots of pooled L4/5 DRG revealed no detectable modification of the expression levels of $\mathrm{Na}_{\mathrm{v}}$ total, nor that of $\mathrm{Na}_{\mathrm{v}} 1.7(P=$ $0.039)$ or $\mathrm{Na}_{v} 1.8(P=0.024) 1$ week after SNI (Figure 3D). However, $\mathrm{Na}_{v} 1.7$ and $\mathrm{Na}_{\mathrm{v}}$ total levels were significantly increased in the sciatic nerve. $\mathrm{Na}_{v} 1.8$ was undetectable in the nerves of sham-operated animals. The signal intensity was not significantly modified after SNI, but a distinct band at the expected molecular weight $(230-240 \mathrm{kDa})$ was visible in all 4 SNI samples (see Supplemental Figure 3B). 

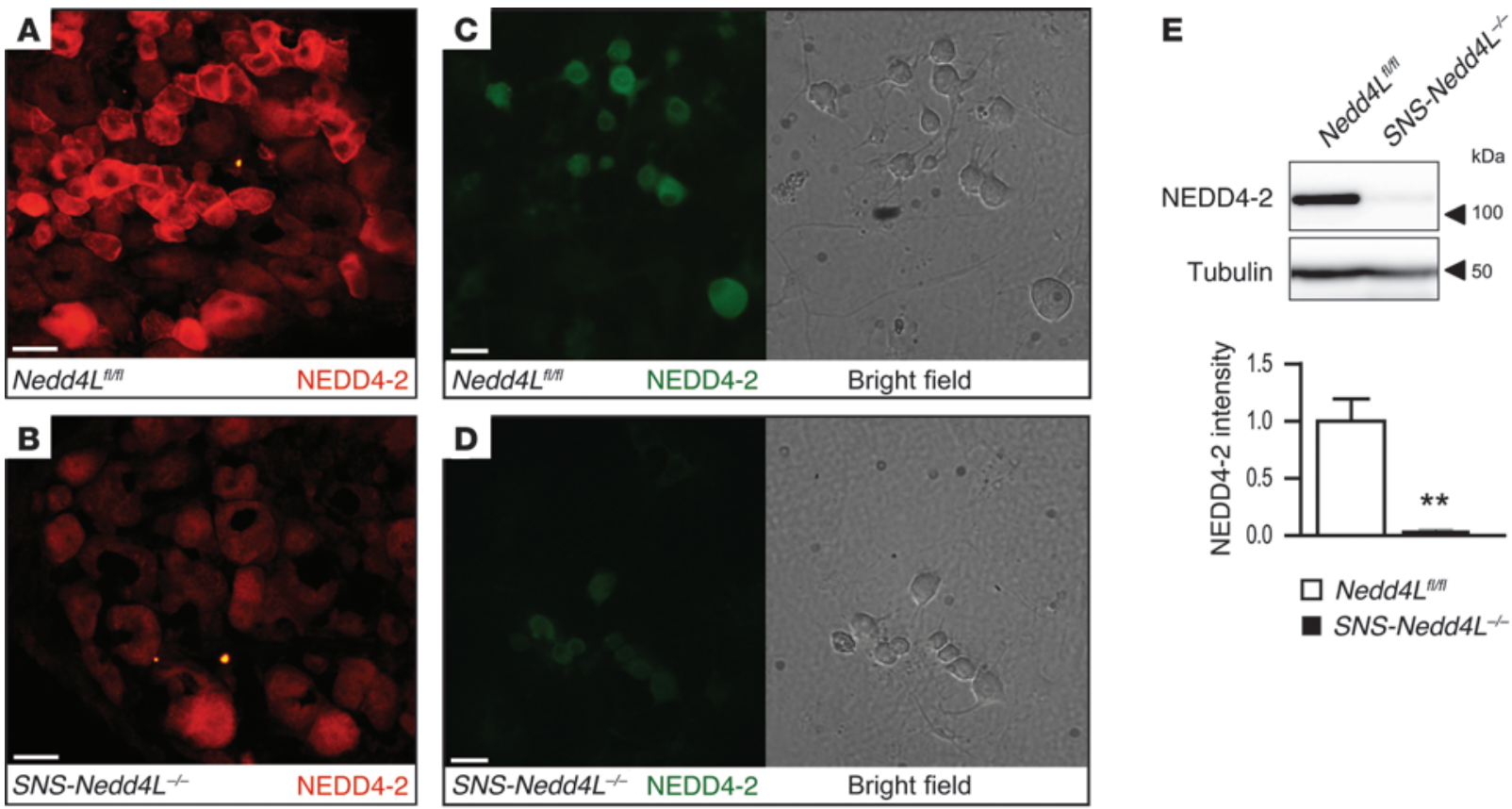

H

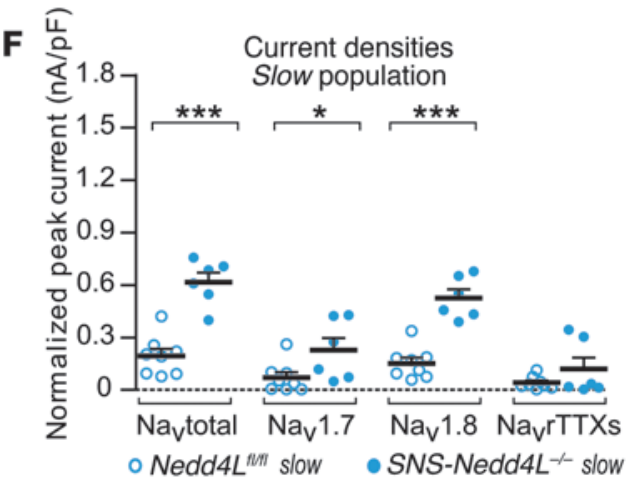

G

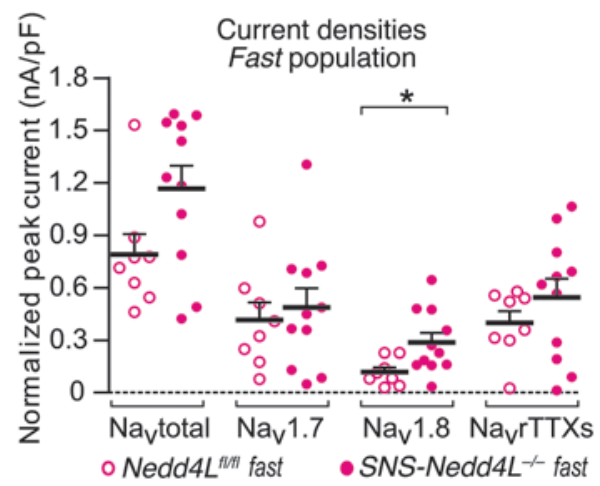

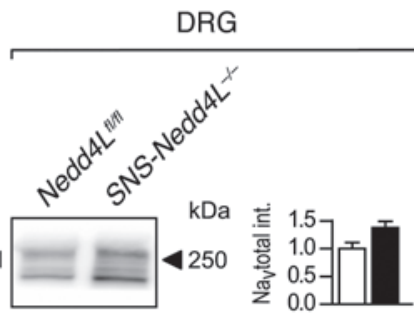

$\mathrm{Na}_{\mathbf{v}} 1.7$

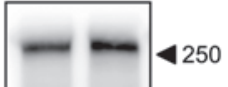

.ே. 1.5
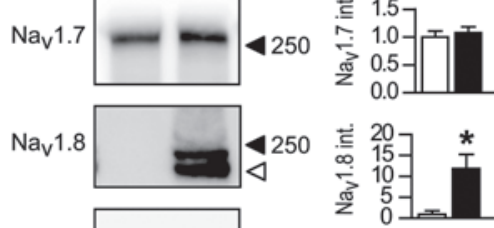

Tubulin

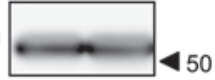

$\square$ Nedd $4 L^{\text {MI }}$

SNS-Nedd $4 L^{-}$

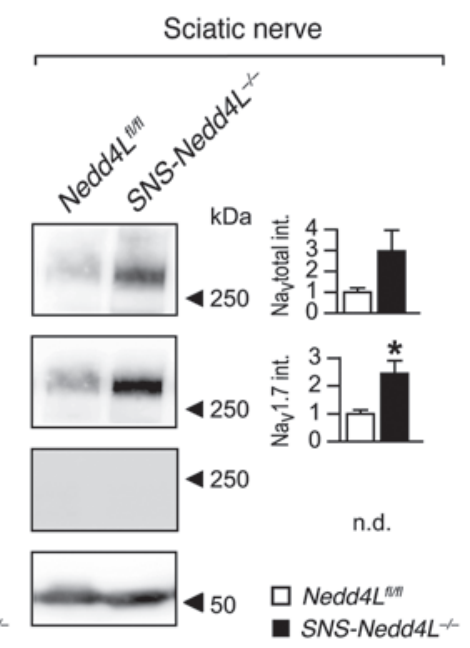

\section{Figure 4}

SNS-Nedd4L $L^{-1-}$ mice show increased $\mathrm{Na}_{v} 1.7$ and $\mathrm{Na}_{v} 1.8$ currents in DRG neurons and increased expression of $\mathrm{Na}_{v} 1.7$ along the sciatic nerve. (A and $\mathbf{B}$ ) Immunofluorescence of NEDD4-2 in coronal sections of L4 DRG from Nedd4L $L^{f l f l}$ and SNS-Nedd $4 L^{-/-}$mice. Scale bars: $30 \mu \mathrm{m}$. (C and D) Immunofluorescence and corresponding bright-field images of NEDD4-2 in DRG neurons from Nedd4L $L^{f l f l}$ and SNS-Nedd4L $L^{-/-}$mice after whole-cell patch-clamp recordings (36 hours after dissociation). Scale bars: $30 \mu \mathrm{m}$. (E) Western blot and quantification showing NEDD4-2 decrease in the DRG $\left({ }^{* *} P=0.003\right)$ of SNS-Nedd4L $L^{-1-}$ mice compared with control Nedd $4 L^{f / f f l}$ mice. (F and $\mathbf{G}$ ) Scatter dot plots representing $\mathrm{Na}_{\mathrm{v}}$ total, $\mathrm{Na}_{\mathrm{v}} 1.7, \mathrm{Na}_{\mathrm{v}} 1.8$, and $\mathrm{Na}_{\mathrm{v}} \mathrm{rTT}$ Xs current densities in L4/5 DRG neurons from SNS-Nedd4L $L^{-/}$and Nedd $4 L^{f l / f l}$ mice. Slow (F, in cyan) and fast (G, in magenta) neurons are shown. Mann-Whitney $U$ test. See Supplemental Figure 4A for total population and Supplemental Table 3 for values and biophysical properties. (H) Left panel: Western blot analysis and quantification of $\mathrm{Na}_{v} \alpha$ subunits in the DRG of SNS-Nedd $4 L^{-1-}$ and Nedd4L $L^{\text {fl/fl }}$ mice. No significant modifications in $\mathrm{Na}_{\mathrm{v}}$ total $(P=0.054)$ or $\mathrm{Na}_{\mathrm{v}} 1.7(P=0.646)$ were observed, whereas the $\mathrm{Na}_{v} 1.8$ signal was increased in the SNS-Nedd4L $L^{-1-}$ mice $\left({ }^{*} P=0.020\right)$. Right panel: same as above, but for sciatic nerves. $\mathrm{Na}_{\mathrm{v}} 1.7$ was significantly increased $\left({ }^{*} P=0.022\right)$, whereas the increase in Navtotal was not significant $(P=0.089)$. Data are expressed as the means $\pm \mathrm{SEM} ; n=4$ samples for each group. Student's $t$ test. Tubulin was used as a loading control in $\mathbf{E}$ and $\mathbf{H}$. 
A

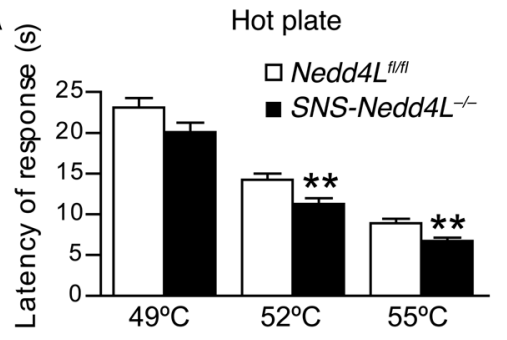

$\mathbf{E}$

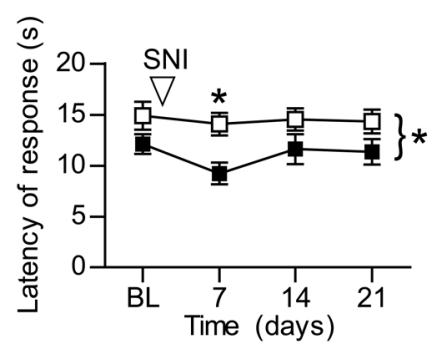

B
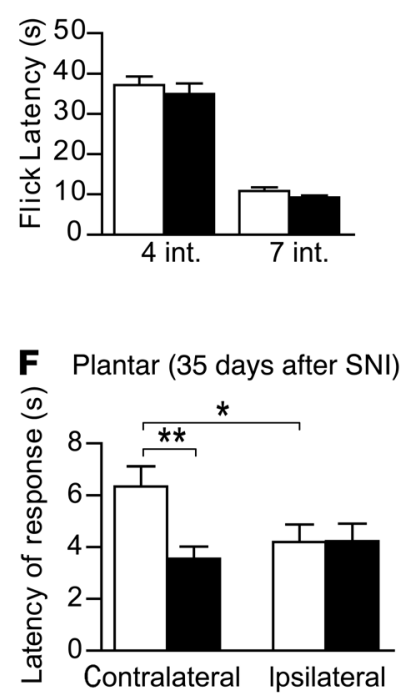

C Tail pressure

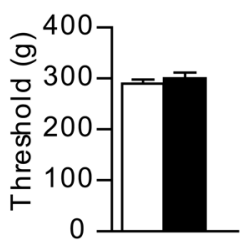

D

von Frey filaments

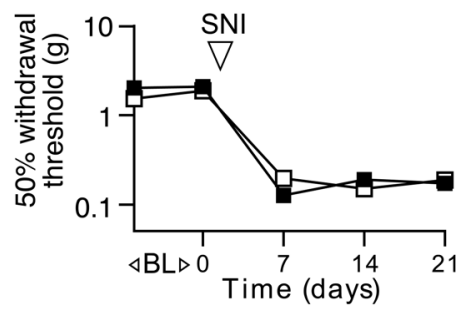

G

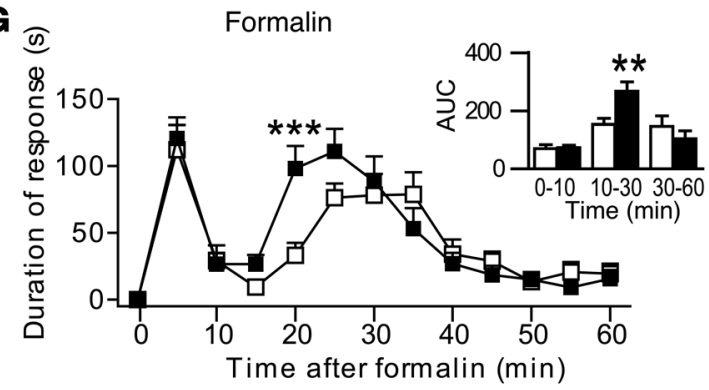

Figure 5

SNS-Nedd $4 L^{-/-}$mice show increased thermal sensitivity and an increased second pain phase after formalin injection. (A) Significantly higher thermal sensitivity was detected in the hot-plate test at $52^{\circ} \mathrm{C}$ and $54^{\circ} \mathrm{C}$ in $S N S-N e d d 4 L^{-l-}$ mice. $P=0.112$ at $49^{\circ} \mathrm{C}$, ${ }^{* *} P=0.009$ at $52^{\circ} \mathrm{C}$, and ${ }^{\star \star} P=0.008$ at $55^{\circ} \mathrm{C}$; Mann-Whitney $U$ test. (B) No differences were observed in the tail-flick test. $P=0.414$ at intensity 4 and $P=0.830$ at intensity 7 (AU); Mann-Whitney $U$ test. (C) Responses to the tail pressure test were unchanged. $P=0.452$, Student's $t$ test. (D) Basal responses to mechanical stimulation and development of SNI-related mechanical allodynia-like behavior were not different. $P>0.05,2$-way ANOVA on log values with post-hoc Bonferroni's tests. (E) Higher thermal sensitivity was detected at $52^{\circ} \mathrm{C}$ in $S N S-N e d d 4 L^{-1-}$ mice, but this effect was not further increased after SNI. ${ }^{*} P<0.05$ between groups using 2-way ANOVA with repeated measures. ${ }^{*} P<0.05$ on day 7 with post-hoc Bonferroni's tests. (F) Plantar test 35 days after SNI. Higher thermal sensitivity was detected in SNS-Nedd4L-/- mice as compared with the noninjured paws of $N e d d 4 L^{f l / f l}$ mice (contralateral). SNI induced thermal hyperalgesia in the injured paws of $N e d d 4 L^{\mathrm{fllfl}}$ mice compared with noninjured paws. ${ }^{*} P=0.013$ and ${ }^{* \star} P=0.006$ at intensity $3(\mathrm{AU})$, Student's $t$ test. $(\mathbf{G})$ Time course of the nocifensive response to formalin injection revealed an increased response in SNS-Nedd4L $L^{-1-}$ mice during the second phase of the test. ${ }^{* * *} P<0.001,2$-way ANOVA with repeated measures with post-hoc Bonferroni's tests. Insert shows the bar graph of this effect through AUC quantification. ${ }^{* \star} P=0.009$, Mann-Whitney $U$ test. Data are expressed as the means $\pm \mathrm{SEM}$ and $n=7-28$ animals per group for all panels.

$N a_{v}$ expression in SNS-Nedd4L $L^{-/-}$knockout mice. To investigate the contribution of NEDD4-2 to the expression of $\mathrm{Na}_{v} \mathrm{~s}$ in DRG in vivo and its impact on pain, a DRG neuron-specific Nedd4Ldeficient mouse line was generated (SNS-Nedd4L $L^{-/-}$; see Supplemental Methods). Mice carrying a homozygous Nedd4L flox allele $\left(\right.$ Nedd $\left.4 L^{f l f l}\right)(30)$ were crossed with mice heterozygously expressing Cre recombinase under the control of the $\mathrm{Na}_{v} 1.8$ promoter (referred to as SNS-Cre), which is predominantly active in DRG nociceptive neurons (31). Cre expression in this mouse line has been extensively characterized (32) and differs from another $\mathrm{Na}_{v} 1.8$ Cre mouse line generated by the Wood laboratory (33). NEDD4-2 expression was greatly reduced in the DRG neurons of SNSNedd $4 L^{-/-}$mice (Figure 4, A-E). A slight signal was still detectable in the SNS-Nedd4L $L^{-/-}$mice, most likely due to a residual expression of NEDD4-2 in neurons not expressing $\mathrm{Na}_{v} 1.8$ (Figure 4E). Wholecell patch-clamp recordings showed a 2-fold upregulation of $\mathrm{Na}_{v^{-}}$ total, $\mathrm{Na}_{v} 1.7(P=0.027)$, and $\mathrm{Na}_{v} 1.8(P<0.001)$ current densities in neurons from SNS-Nedd4L $L^{-/-}$mice (Supplemental Figure 4A and Supplemental Table 3) compared with neurons from Nedd $4 L^{f / f l}$ control littermates. The $\mathrm{Na}_{\mathrm{v}}$ rTTXs component was not significantly altered. Subsequent analyses of slow and fast neuronal subpopulations revealed that, similar to the SNI condition, the changes were predominant in slow neurons (a 2-fold increase for $\mathrm{Na}_{\mathrm{v}}$ total $[P=0.001], \mathrm{Na}_{v} 1.7[P=0.042]$, and $\mathrm{Na}_{v} 1.8[P<0.001]$ current densities) (Figure 4, F and G). The biophysical properties were largely unaltered in the knockout mice (Supplemental Table 3 ), consistent with a major role of NEDD4-2 in the regulation of $\mathrm{Na}_{v} 1.7$ and $\mathrm{Na}_{\mathrm{v}} 1.8$ membrane density.

We then evaluated whether the expression of $\mathrm{Na}_{\mathrm{v}} \mathrm{S}$ was modified in DRG and the sciatic nerves of SNS-Nedd4L $\mathrm{L}^{-/-}$mice (Figure 4H). We observed a markedly increased Western blot signal for $\mathrm{Na}_{v} 1.8$ in the DRG of knockout mice, while the signal was undetectable in Nedd $4 L^{f l f l}$ DRG neurons. These observations were confirmed by immunofluorescence measurements (Supplemental Figure 4B). Although the $\mathrm{Na}_{v} 1.7$ signal from DRG was not changed between the groups, a stronger signal was observed in the sciatic nerves of the SNS-Nedd4L $L^{-/-}$mice, similar to that observed after SNI. $\mathrm{Na}_{\mathrm{v}} 1.8$ immunoreactivity was not detected in the sciatic nerves of the knockout mice or in those of the control mice, suggesting that the mechanisms underlying $\mathrm{Na}_{\mathrm{v}} 1.8$ redistribution in nerves after $\mathrm{SNI}$ are independent of NEDD4-2 downregulation.

Pain-related responses in SNS-Nedd4L $L^{-1-}$ knockout mice. We then investigated whether peripheral deficiency of NEDD4-2 could modify pain behavior. While response latencies to radiant heat (tail-flick test) (Figure 5B) and acute mechanical nociception (tail pressure test) (Figure 5C) were unchanged, acute thermal hypersensitivity in SNS-Nedd4L $\mathrm{L}^{-/-}$mice was observed with the hot-plate test at $52^{\circ} \mathrm{C}$ and $55^{\circ} \mathrm{C}$ (Figure $5 \mathrm{~A}$ ). We also performed the hot- 

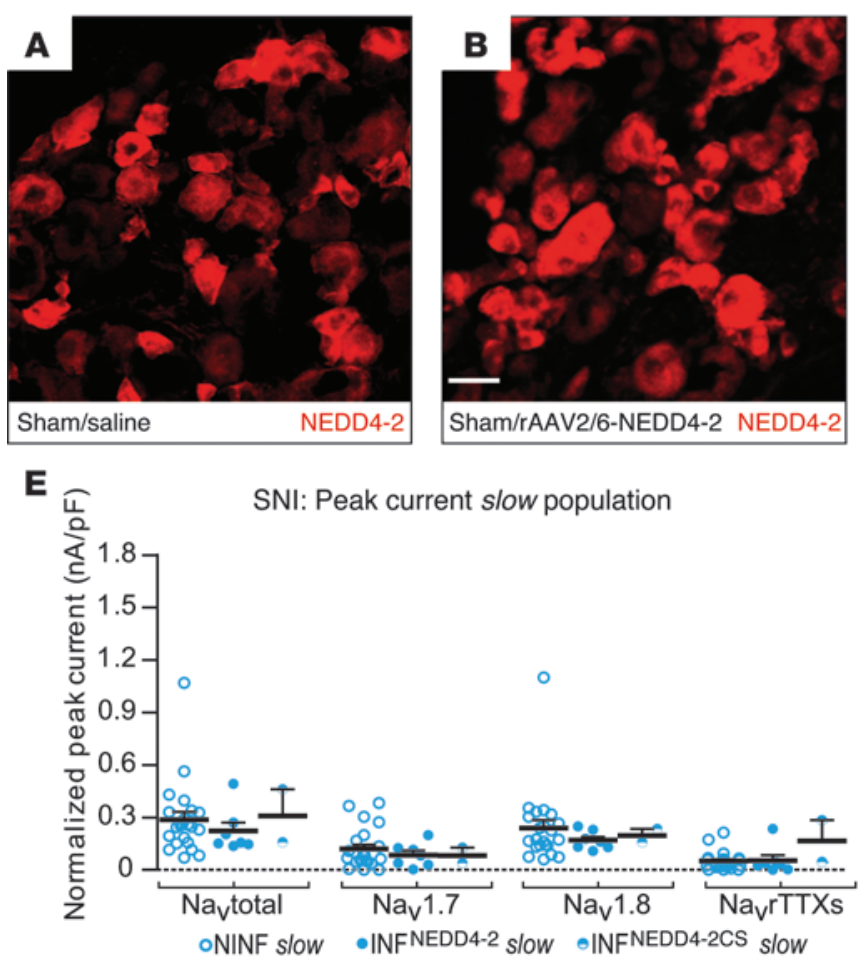

$\mathbf{G}_{0}$

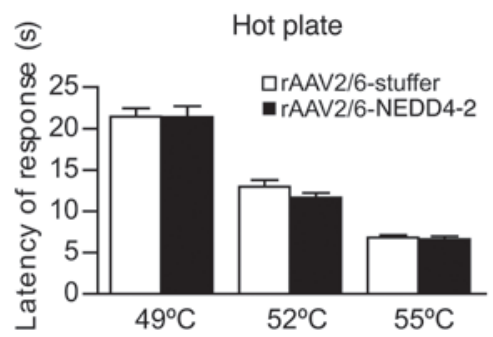

H

Tail flick

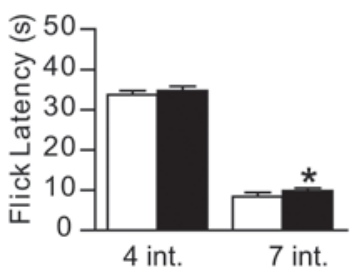

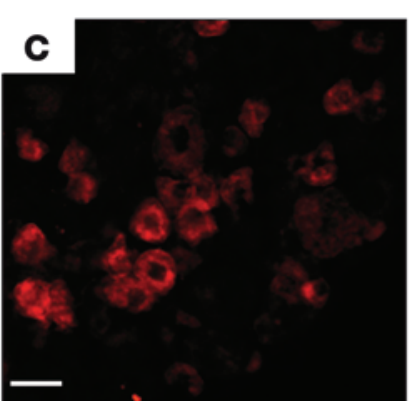

NEDD4-2

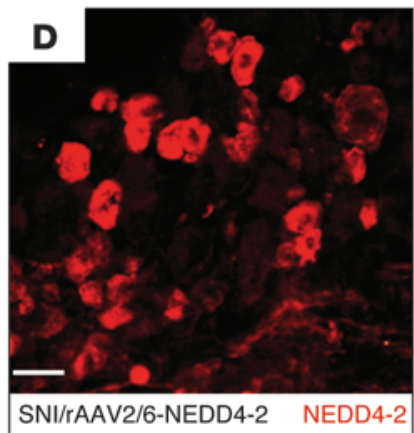

SNI/rAAV2/6-NEDD4-2 NEDD4-2

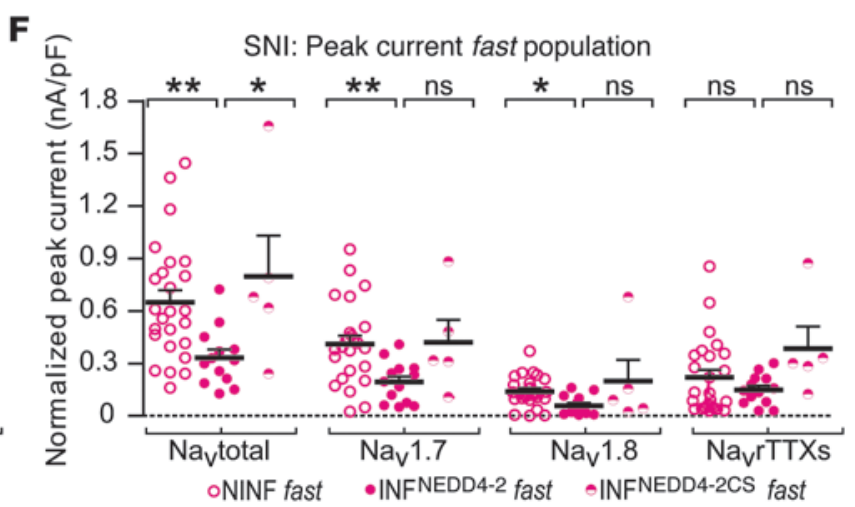

I Tail pressure $\mathbf{J}$

von Frey filaments
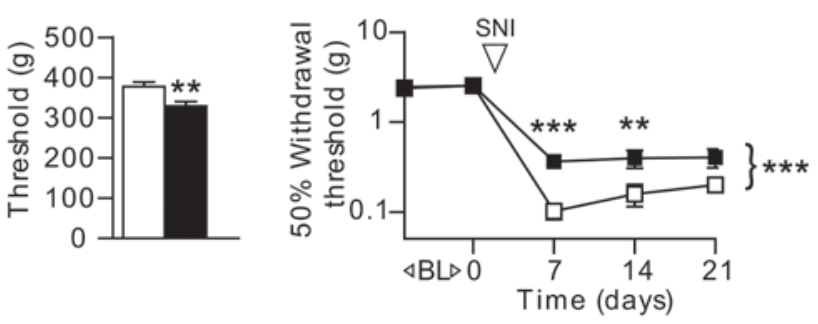

Figure 6

Delivery of rAAV2/6-NEDD4-2 viral vector decreases functional currents after SNI and alleviates mechanical allodynia. (A-D) Immunofluorescence of NEDD4-2 in coronal sections of L4 ipsilateral DRG injected with rAAV2/6-NEDD4-2 or saline solution in sham- and SNI-operated mice. Scale bars: $30 \mu \mathrm{m}$. (E and F) Scatter dot plots representing Navtotal, $\mathrm{Na}_{v} 1.7, \mathrm{Na}_{\mathrm{v}} 1.8$, and $\mathrm{Na}_{v} \mathrm{rTT}$ Xs current densities 1 week after SNI in noninfected DRG neurons (NINF), rAAV2/6-NEDD4-2-infected cells (INFNEDD4-2), and in the control group infected with the rAAV2/6-NEDD4-2CS vector (INFNEDD4-2CS). Slow (E, in cyan) and fast (F, in magenta) neurons are shown. Nonparametric 1-way ANOVA (Kruskal-Wallis test) with Dunn's post-hoc test. See Supplemental Figure 5F for total population, Supplemental Table 5 for biophysical properties and values, and Supplemental Figure 5, A-E. (G) Basal thermal sensitivity showed no difference at $49^{\circ} \mathrm{C}(P=0.987), 52^{\circ} \mathrm{C}(P=0.186)$, or $55^{\circ} \mathrm{C}(P=0.673)$ in the hot-plate test between the 2 groups. Student's $t$ test. (H) An increase in tail-flick latency $(P=0.018$ at intensity 7$)$ for high-intensity stimulation in the rAAV2/6-NEDD4-2 group was observed. Mann-Whitney $U$ test. (I) Tail pressure sensitivity was increased in mice infected with rAAV2/6-NEDD4-2. ${ }^{* \star} P=0.006$, Student's $t$ test. (J) Basal responses to innocuous mechanical stimulation were not different between the 2 strands, but the development of mechanical allodynia was significantly diminished in rAAV2/6-NEDD4-2-infected mice. ${ }^{* \star} P<0.001$ at day 7 and ${ }^{* \star} P<0.01$ at day 14 ; 2-way ANOVA on log values with post-hoc Bonferroni's tests. Data are expressed as the mean $\pm \mathrm{SEM} ; n=12-15$ for $\mathrm{rAAV} 2 / 6$-stuffer and rAAV2/6-NEDD4-2.

plate test at $52^{\circ} \mathrm{C}$ after SNI (Figure $5 \mathrm{E}$ ). Nedd $4 \mathrm{~L}^{\mathrm{fl} / \mathrm{fl}}$ mice did not develop SNI-induced hyperalgesia. The observed thermal hypersensitivity in the SNS-Nedd $4 L^{-/-}$mice under basal conditions was not further enhanced after SNI. The response of the hot-plate test depends on the strength applied by the paw to the plate, which may be impeded after SNI surgery due to the transection of motor neurons. To overcome this problem, we performed the plantar test, an alternative thermal sensitivity test independent of strength, at the end of the SNI time course (i.e., 35 days after SNI). As illustrated in Figure 5F, the noninjured paws of SNS-Nedd4L $\mathrm{L}^{-/-}$mice demon- strated more thermal hypersensitivity than the noninjured paws of Nedd $4 L^{\ell / / f l}$ mice. SNI induced thermal hypersensitivity in the injured paws of Nedd $4 L^{f / f l}$ mice, but did not further enhance the hypersensitivity in the injured paws of SNS-Nedd $4 L^{-/-}$mice. Basal mechanical innocuous sensitivity was not altered in Nedd $4 L^{f / f l}$ mice (see baseline [BL] in the von Frey filaments test in Figure 5D). After SNI, the decrease in the withdrawal threshold related to the development of mechanical allodynia-like behavior was indistinguishable between groups. Intraplantar injection of formalin in SNS-Nedd $4 L^{-/-}$mice led to an increased and earlier maximal 
response (peak at $30.4 \pm 1.4$ minutes in SNS-Nedd44 $L^{-/-}$mice compared with $36.3 \pm 1.3$ minutes in Nedd $4 L^{f / f l}$ mice; $P=0.039$ ) during the early second phase as compared with the Nedd $4 L^{f / f l}$ mice, suggesting a central consequence of increased peripheral activity due to Nedd4L deletion (Figure 5G). Acute nociception during phase 1 of the formalin test was similar between the groups.

Functional effects of in vivo exogenous NEDD4-2 overexpression. To test whether the rescue of NEDD4-2 reduction in DRG may functionally modify $\mathrm{Na}_{v}$ expression and influence the course of SNI-induced hypersensitivity, we generated a recombinant serotype 6 adenoassociated viral vector expressing NEDD4-2 (rAAV2/6-NEDD4-2, Supplemental Figure 5A). Two control vectors were designed: noncoding (stuffer) vectors and those expressing the catalytically inactive form of NEDD4-2 (NEDD4-2CS). The infection efficiency of the viral vector was recently demonstrated for small DRG neurons (presumably nociceptors) after intrathecal delivery, and the transduction efficiency was shown to be entirely preserved after peripheral nerve injury (34). Immunofluorescence experiments showed that rAAV2/6-NEDD4-2 increased NEDD4-2 expression in L4/5 DRG under naive conditions and after SNI (Figure 6, A-D and Supplemental Figure $5 \mathrm{~B}) . I_{\mathrm{Na}}$ measurements were taken of small DRG neurons after Nedd4L gene delivery, followed by single-cell PCR to identify infected (INF) and noninfected neurons (NINF). In naive animals, NEDD4-2 overexpression altered neither the $I_{\mathrm{Na}}$ density, nor the biophysical properties of rAAV2/6-NEDD4-2-infected DRG neurons when compared with cells infected with the control vector (INFNEDD4-2CS) or the NINF neurons (Supplemental Figure 5, C-E, and Supplemental Table 4). In the SNI condition, exogenous expression of NEDD4-2 substantially reduced the $I_{\mathrm{Na}}$ densities for $\mathrm{Na}_{v}$ total (by $49 \%$ ), $\mathrm{Na}_{v} 1.7$ (by $53 \%$ ), and $\mathrm{Na}_{\mathrm{v}} 1.8$ (by $58 \%$ ) of infected neurons (INFNEDD4-2). This was observed mainly in the fast subpopulation of DRG neurons as compared with the controls (INFNEDD4-2CS and NINF; Figure 6F and Supplemental Table 5), accounting for the tendency observed in the total population (Supplemental Figure 5F). The virus can potentially transduce all types of DRG cells, which may explain why effects were observed only in the fast population and not in the slow population. Before determining whether restoring NEDD4-2 expression with this viral vector would impact SNImediated hypersensitivity, we first tested the basal sensitivity. The response to innocuous mechanical stimuli remained unchanged (see baseline in the von Frey filaments test; Figure 6J). Responses to the hot-plate test (Figure 6G) and the low intensity of the tailflick tests were not different between rAAV2/6-NEDD4-2 or control vector (rAAV2/6-stuffer) mice (Figure $6 \mathrm{H}$ ). However, mice infected with rAAV2/6-NEDD4-2 showed mild, but significant, hyposensitivities to the higher stimulus of the tail-flick test, whereas they showed mild, but significant, hypersensitivity to mechanical nociception (tail pressure test; Figure 6I). The development of mechanical allodynia following SNI was repressed in rAAV2/6-NEDD4-2infected mice as compared with mice infected with the noncoding vector (Figure 6J), highlighting the behavioral consequences of the decrease in $I_{\mathrm{Na}}$ current.

\section{Discussion}

The present study provides what we believe to be the first in vivo evidence that the ubiquitin ligase NEDD4-2 exerts a strong influence on the neuronal excitability of the sensory system, and that dysregulation of this regulatory mechanism contributes to pain hypersensitivity. This is mainly due to a pathological redistribution of $\mathrm{Na}_{v} 1.7$ and $\mathrm{Na}_{v} 1.8$ in DRG cells.
Peripheral neuropathic pain develops across different disease states as a result of different mechanisms and depends on multiple etiological factors. In this study, we used the SNI model, a common traumatic nerve injury-induced neuropathic pain animal model (35). Although this may not mimic the mechanisms of other neuropathic pain syndromes, its fast onset and prolonged maintenance of thermal and mechanical hypersensitivity renders it very valuable.

Using this model of neuropathic pain in mice, NEDD4-2 expression was found to be substantially decreased in DRG neurons, with a concomitant increase in $\mathrm{Na}_{v} 1.7$ and $\mathrm{Na}_{v} 1.8$ current densities. The results also demonstrated that knocking out NEDD4-2 expression in nociceptive neurons increased $\mathrm{Na}_{v} 1.7$ and $\mathrm{Na}_{v} 1.8$ levels and enhanced basal pain sensitivity. Conversely, the overexpression of NEDD4-2 using rAAV2/ 6 vectors led to a reduction in $\mathrm{Na}_{\mathrm{v}} 1.7$ and $\mathrm{Na}_{\mathrm{v}} 1.8$ current densities and a decrease in neuropathic pain-like allodynia in the SNI model.

The different components of $I_{\mathrm{Na}}$ were identified in mouse DRG neurons by the use of specific electrophysiological protocols and toxins. $\mathrm{Na}_{\mathrm{v}} 1.7$-mediated currents were isolated with the perfusion of ProTxII (26). SNI increased $\mathrm{Na}_{\mathrm{v}} 1.7$ and $\mathrm{Na}_{\mathrm{v}} 1.8$ currents, particularly in the slow neuron subpopulation. Because the biophysical properties of the different $I_{\mathrm{Na}}$ components were not modified in the slow subpopulation, it is unlikely that the increased current density encountered after SNI was due to a modification of single-channel properties. The results suggest that an increased number of functional channels at the cell membrane may be responsible, a mechanism to which NEDD42 downregulation may contribute. This hypothesis is supported by the results obtained with the SNS-Nedd4L $\mathrm{L}^{-/-}$mice, in which an increase in $\mathrm{Na}_{\mathrm{v}}$ 1.7/1.8 current densities was also observed in slow neurons and is unlikely due to the modification of single-channel properties. The specific roles of fast/slow neuronal subpopulations are not yet understood, but the present observations suggest a role for the slow population in modulating thermal sensation.

The protein levels in DRG result from the large intracellular pool of $\mathrm{Na}_{\mathrm{v}} \mathrm{s}$ and the small $\mathrm{Na}_{\mathrm{v}}$ fraction at the plasma membrane (36). As a consequence, modifications of $\mathrm{Na}_{v}$ expression that would be restricted to the plasma membrane may be below the sensitivity limits of the assay, thus accounting for the lack of observed modification of $\mathrm{Na}_{\mathrm{V}}$ expression in DRG. Interestingly, both SNI and SNS-Nedd4L $L^{-/-}$mice showed an accumulation of $\mathrm{Na}_{\mathrm{v}} 1.7$ along the sciatic nerve, suggesting NEDD4-2 involvement in channel axonal trafficking. The generation of SNS-Nedd $4 L^{-/-}$mice enabled us to investigate the functional contribution of NEDD4-2 in pain pathways. These mice exhibit an abnormal pain phenotype with increased noxious heat sensitivity, as revealed in both the hot-plate and plantar tests under basal conditions. Interestingly, the increase in thermal hypersensitivity seen with the plantar test in the SNSNedd $4 L^{-/-}$mice reached similar levels to those seen after SNI in the injured paws of control littermates. This finding suggests that genetic disruption of NEDD4-2 leads to thermal pain hypersensitivity similar to that observed when NEDD4-2 is pathologically decreased after SNI. Because SNS-Nedd4L $\mathrm{L}^{-/-}$ mice did not develop mechanical allodynia under basal conditions, the decrease in NEDD4-2 is probably not sufficient to render these mice mechanically hypersensitive. Neither thermal nor mechanical hypersensitivity was enhanced in SNS-Nedd $4 \mathrm{~L}^{-/-}$ 
mice after SNI, suggesting that a maximum effect of SNI-induced hypersensitivity was reached. This is consistent with the fact that NEDD4-2 cannot be further decreased, or only to a

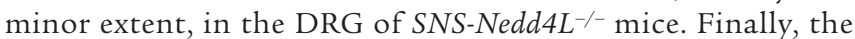
responses in the early second phase of the formalin test were increased, and the kinetics were accelerated in SNS-Nedd4L $L^{-/-}$ mice when compared with their controls. This result suggests that the peripheral deletion of NEDD4-2 enhances noxious/ nocive inputs in the dorsal horn and that it may be sufficient to impact the global mechanisms of central sensitization (37).

The pain behavior of the SNS-Cre mouse line does not differ from that of wild-type littermates (38), suggesting that the observed hypersensitive phenotype is due to the deletion of NEDD4-2 and not to the expression of Cre recombinase in $\mathrm{Na}_{\mathrm{v}} 1.8$-positive nociceptors. The possibility that these differences may also involve non-nociceptive neurons that are potentially subject to Cre recombination cannot be ruled out, as $\mathrm{Na}_{\mathrm{v}} 1.8$ expression was recently shown to extend to larger DRG neurons (39).

Major modifications of $\mathrm{Na}_{\mathrm{v}} 1.8$ and $\mathrm{Na}_{\mathrm{v}} 1.7$ density and distribution were observed in this study. Despite their well-established roles in nociception, the mechanisms by which $\mathrm{Na}_{\mathrm{v}} 1.7$ and $\mathrm{Na}_{\mathrm{v}} 1.8$ isoforms specifically contribute to neuropathic pain are still under debate. On the one hand, knocking down $\mathrm{Na}_{\mathrm{v}} 1.8$ prevents neuropathic pain in mice (40), $\mathrm{Na}_{\mathrm{v}} 1.7$ accumulates in human painful dental pulp (15), and gain-of-function mutations of $\mathrm{Na}_{\mathrm{v}} 1.7$ and $\mathrm{Na}_{\mathrm{v}} 1.8$ are linked to exaggerated pain in humans $(12,13)$. A recent simulation study suggested that $\mathrm{Na}_{v} 1.7$ and $\mathrm{Na}_{v} 1.8$ may act synergistically to increase the amplitude of subthreshold oscillations and increase the frequency of repetitive firing in the periphery (41). Increasing their expression in slow neurons might promote hyperexcitability. However, in sensory neuron-specific knockouts of $\mathrm{Na}_{\mathrm{v}} 1.7, \mathrm{Na}_{\mathrm{v}} 1.8$ or double-knockout mice, neuropathic pain-like behavior still develops after nerve injury (18-20). It must be noted that compensatory effects in the expression of the different $\mathrm{Na}_{v}$ isoforms in genetically modified animals during development cannot be excluded. The accumulation of $\mathrm{Na}_{\mathrm{v}} 1.7$ and $\mathrm{Na}_{\mathrm{v}} 1.8$ observed along the sciatic nerve after SNI has already been reported for $\mathrm{Na}_{\mathrm{v}} 1.8$ in an experimental neuropathic pain model and was reported to contribute to neuropathic pain (14).

In the present study, counteracting the SNI-mediated decrease in NEDD4-2 using gene transfer further supports the functional importance of this ubiquitin ligase in traumatic nerve injury-induced neuropathic pain. Gene transfer has already been successfully used in mice to alleviate pain (42), and clinical trials with vectors engineered to express the preproenkephalin gene for treating cancer pain are underway (43, 44). In this study, rAAV-mediated overexpression of NEDD4-2 led to a decrease in $\mathrm{Na}_{\mathrm{v}} 1.7$ and $\mathrm{Na}_{\mathrm{v}} 1.8$ current densities in fast DRG neurons, which was concomitant with the prevention of the full development of mechanical allodynia. It may be that rAAV overexpression of NEDD4-2 after nerve injury prevents an excess of abnormal peripheral input and reduces activitydependent central sensitization. It is unlikely that the effects on mechanical allodynia are due to peripheral changes in the activation threshold of low-threshold mechanical afferent fibers, since basal mechanical sensitivity was minimally or not at all affected by rAAV-NEDD4-2 (nor was it after NEDD4-2 knockout). The unexpected mechanical hypoalgesic effect of rAAV2/6-NEDD4-2 might be due to the ability of ubiquitin ligase to regulate other ion channels, such as voltage-gated potassium or chloride channels (45), which could inversely affect cellular excitability depending on the targeted neuronal subpopulation. Despite its effect on the $I_{\mathrm{Na}}$ of fast DRG neurons, other effects of the viral vector $\mathrm{rAAV} 2 / 6$ on cells or fibers in the peripheral nerve cannot be ruled out.

NEDD4-2 was identified as a central in vivo posttranslational regulator of $\mathrm{Na}_{\mathrm{v}} 1.7$ and $\mathrm{Na}_{\mathrm{v}} 1.8$, whose altered function may contribute to the development of neuropathic pain. Given that the abnormal functioning of sodium channels is a key event in the etiology of neuropathic pain, these results support a new paradigm in the treatment of this pathology. Ubiquitylation-dependent mechanisms have already been implicated in neuropathic pain in a study reporting that the intrathecal delivery of proteasome inhibitors attenuated hyperalgesia in rats (46). Another posttranslational modification of sodium channels induced by the accumulation of the glycolytic metabolite methylglyoxal was recently found to play an important role in diabetic neuropathy (47). Posttranslational modifications of $\mathrm{Na}_{\mathrm{v}} 1.8$ accounted for small, but significant, changes in the biophysical properties of the channel and were responsible for increased excitability of primary sensory neurons and sensitivity in diabetic mice. These results, together with the findings of this study, strongly support the need to look for agents that can modulate $\mathrm{Na}_{\mathrm{v}}$ function and that can act as alternatives to the $\mathrm{Na}_{\mathrm{v}}$ blockers currently used to treat neuropathic pain.

The factors that lie upstream of the observed NEDD4-2 decrease remain to be identified. Similar to many downregulated genes after SNI, axonal injury and the deprivation of trophic factors from the target tissue likely influence the transcriptional mechanisms involved in the NEDD4-2 decrease (48).

These results point to NEDD4-2 as a central regulator of nociception and demonstrate that NEDD4-2 dysfunction leads to pathological pain. The enhancement of NEDD4-2 activity may provide a novel mechanistic alternative to sodium channel blockers for the treatment of neuropathic pain. NEDD4-2 may even be involved in other neurological diseases linked to altered $\mathrm{Na}_{v}$ channel activity, such as epilepsy and migraine headaches.

\section{Methods}

\section{DNA constructs}

Human Nedd4L (KIAA0439) cDNA lacking a C2 lipid-binding domain cloned into pcDNA3.1 was a gift from T. Nagase (Kazusa DNA Research Institute, Kisarazu, Japan). $\mathrm{Na}_{\mathrm{v}} 1.7 \mathrm{cDNA}$ cloned into pCIN5h was provided by S. Tate (Convergence Pharmaceuticals). The QuickChange mutagenesis kit (Stratagene) was used to generate $\mathrm{Na}_{\mathrm{v}} 1.7$ and NEDD4-2 mutants. $\mathrm{Na}_{\mathrm{v}} 1.7$ C-terminal PY mutants were generated as follows: Pro ${ }^{1944}$ was mutated into Ala to generate the PA mutant, Tyr ${ }^{1947}$ into Ala to generate the YA mutant, and $\mathrm{Val}^{1950}$ into Ala to generate the VA mutant. The NEDD4-2CS mutant was generated by mutating Cys ${ }^{801}$ into a Ser. shRNA against NEDD4-2 cloned into a PGIPZ lentiviral vector was obtained from Open Biosystems. For pull-down experiments, the cDNAs encoding the 66 last amino acids of $\mathrm{Na}_{\mathrm{v}} 1.7$, the 3 different PY mutants, and the ubiquitin-binding proteasomal subunit S5A (GST$\mathrm{S} 5 \mathrm{~A}$ ) were cloned into pGEX-4T1 (Amersham Bioscience) to generate GST fusion proteins.

Western blots, immunofluorescence

See Supplemental Methods. 


\section{Pull-down and ubiquitylation experiments}

pGEX-4T1 containing GST fused to the 66 last amino acids of $\mathrm{Na}_{v} 1.7 \mathrm{WT}$ and PY mutants, as well as GST fused to ubiquitin-binding proteasomal subunit S5A proteins, were produced (see Supplemental Methods). Pulleddown proteins were analyzed by Western blot.

\section{Cell-surface biotinylation}

HEK293 cells were incubated for 30 minutes at $4{ }^{\circ} \mathrm{C}$ with biotin solution $(0.5$ $\mathrm{mg} / \mathrm{ml}$ biotin in cold PBS; Pierce Biotechnology) and then rinsed 2 times with PBS containing $200 \mathrm{mM}$ glycine followed by 2 rinsings with PBS. Cells were then solubilized for 1 hour at $4^{\circ} \mathrm{C}$ on a wheel, and $50 \mu \mathrm{l}$ of streptavidinneutravidin-sepharose beads (Invitrogen) was incubated in this fraction for binding to biotinylated proteins. Samples were analyzed by Western blotting.

\section{Real-time RT-PCR}

See Supplemental Methods.

\section{Cell culture and transfection}

See Supplemental Methods.

\section{Neuron primary culture \\ See Supplemental Methods.}

\section{Mouse lines}

See Supplemental Methods.

\section{Animal surgery}

In the SNI experiments, the biceps femoris was incised, exposing the sciatic nerve. The tibial and common peroneal nerves were ligated with a silk suture (Ethicon) and transected (35).

\section{Viral vector and intrathecal injection}

See Supplemental Methods.

\section{Behavioral pain tests}

Hot-plate assay. The hot-plate assay was conducted by placing the animals on the hot-plate surface set at varying temperatures $\left(49^{\circ} \mathrm{C}, 52^{\circ} \mathrm{C}\right.$, and $\left.55^{\circ} \mathrm{C}\right)$. The latency of response (in seconds) was determined by a hind paw lick or jump. The cutoff was adjusted for each temperature to avoid tissue damage (60 seconds for $49^{\circ} \mathrm{C}, 30$ seconds for $52^{\circ} \mathrm{C}$, and 20 seconds for $55^{\circ} \mathrm{C}$ ).

Tail-flick assay. The tail-flick assay was conducted using a tail-flick analgesia meter, and the mice were gently restrained in a conical plastic cloth. The latency of response (in seconds) was recorded at 2 different light beam intensities (4 and $7 \mathrm{AU}$ ).

Pincher test. The pincher test consists of a pair of large blunt forceps (15 cm long; flat contact area: $7 \mathrm{~mm} \times 1.5 \mathrm{~mm}$ with smooth edges) equipped with 2 strain gauges connected to a modified electronic dynamometer (Bioseb). The tips of the forceps were placed around the tail of the tested mice, and the force applied was incremented by hand until a withdrawal response occurred. The measurement was repeated 3 times, and the mean force (in grams) that induced withdrawal was calculated.

von Frey assay. The von Frey assay was conducted by applying a series of calibrated von Frey filaments on the lateral side of the hind paw's plantar surface (sural nerve territory). Mice were thus placed on a platform with a wire netting floor. The mechanical stimulus producing a 50\% likelihood of withdrawal was determined using the up-down method.

Formalin test. The formalin test was conducted by injecting $10 \mu \mathrm{l}$ of $5 \%$ formalin subcutaneously into the left hind paw. The time the animal spent shaking or flinching and licking its paw was recorded at 5-minute intervals for 60 minutes.
Plantar test. The plantar test was conducted by exposing the lateral plantar surface of the paw to a beam of radiant heat through a transparent surface. The heat stimulation was repeated 3 times for each paw, and the mean latency time was calculated.

\section{Electrophysiology}

HEK293 cell recordings. The external and internal solutions used were as previously described (ref. 23 and see Supplemental Methods). Data were recorded using a VE-2 amplifier (Alembic Instruments) or an Axon 700A amplifier and analyzed using pClamp software, version 8 (Molecular Devices), KaleidaGraph, version 4.03 (Synergy Software), and MATLAB (The MathWorks). The resistance of the borosilicate pipettes (World Precision Instruments) was 2-6 M . The leakage current was subtracted using the $\mathrm{P} / 4$ procedure.

$I_{\mathrm{Na}}$ densities $(\mathrm{pA} / \mathrm{pF})$ were obtained by dividing the peak $I_{\mathrm{Na}}$ by the cell capacitance obtained from the pClamp function. Current densities were normalized to WT Na 1.7 or pcDNA3.1 (empty vector control) in the stable cell line for each day of the experiment. The $\mathrm{Na}^{+}$current for the steady-state activation (SSA) curves was evoked from a holding potential of $-100 \mathrm{mV}$ to test pulses of $100 \mathrm{~ms}$ ranging from $-120 \mathrm{mV}$ to $+30 \mathrm{mV}$ in increments of $5 \mathrm{mV}$. Steady-state inactivation (SSI) curves were measured from a holding potential of $-120 \mathrm{mV}$ using 500 -ms prepulses to the indicated potentials followed by a test pulse to $0 \mathrm{mV}$. To quantify the voltage dependence of SSA and SSI, data from individual cells were fitted with the Boltzmann relationship, $y(V m)=1 /\left(1+\exp \left[\left(V m-V_{1 / 2}\right) / k\right]\right)$, where $y$ is the normalized current or conductance, $V m$ is the membrane potential, $V_{1 / 2}$ is the voltage at which half of the available channels are inactivated, and $k$ is the slope factor.

The recovery from inactivation (RFI or "repriming") curves were obtained with a standard 2-pulse protocol consisting of a depolarizing pulse from a holding potential of $-120 \mathrm{mV}$ to $0 \mathrm{mV}$ for $50 \mathrm{~ms}$ to inactivate the channels, followed by a variable duration (from $0.5 \mathrm{~ms}$ to $3,000 \mathrm{~ms}$ ) step back to $-120 \mathrm{mV}$ to promote recovery. The availability of the channels was assessed with the first standard test pulse at $0 \mathrm{mV}$, and the normalized currents of the second pulse at $0 \mathrm{mV}$ were plotted versus the recovery interval. We calculated the $t_{1 / 2}(\mathrm{~ms})$, which is the time necessary for half of the channels to recover from the first pulse, by interpolation from a linear relation between the 2 points juxtaposing half recovery $\left(y_{1}<0.5<y_{2}\right)$, using the relation $x=\left[0.5-\left(y_{1} x_{2}-y_{2} x_{1}\right) /\left(x_{2}-x_{1}\right)\right] \times\left(x_{2}-x_{1}\right) /\left(y_{2}-y_{1}\right)$.

$D R G$ neuron recordings. Twelve hours after plating, we performed whole-cell recordings of small neurons $\left(\mathrm{C}_{\mathrm{m}}<30 \mathrm{pF}\right)$ from $\mathrm{L} 4 / 5 \mathrm{DRG}$, thought to be nociceptors (27). We used an EPC-10 amplifier and Patchmaster software (both from HEKA Electronics) for data acquisition and analysis. The external and internal solutions used were as previously described (ref. 49 and see also Supplemental Methods). Pipettes had a resistance of less than $3 \mathrm{M} \Omega$, capacity transients were cancelled, and series resistance was compensated by approximately $90 \%$. We used data only from cells in which the access resistance remained stable throughout the duration of the experiment. The leakage current was digitally subtracted using the $\mathrm{P} / 4$ procedure.

$I_{\mathrm{Na}}$ densities $(\mathrm{pA} / \mathrm{pF})$ were obtained by dividing the peak $I_{\mathrm{Na}}$ by the cell capacitance obtained from the HEKA function. Once in whole-cell configuration, cells were held at $-60 \mathrm{mV}$ for 5 minutes for the following reasons: (a) to dialyze the cell with CsF solution; (b) to reach equilibrium of $\mathrm{Na}_{v} 1.8$ (steady-state activation is shifted to hyperpolarized potentials during the first few minutes because of $\mathrm{CsF}$ ); and (c) to lastingly inactivate the $\mathrm{Na}_{v} 1.9$ current (50) in order to prevent contamination of the $\mathrm{Na}_{\mathrm{v}} 1.8$ current. Cells were clamped at $-80 \mathrm{mV}$ for 2 more minutes before starting the recordings. Activation, SSI, and RFI curves were obtained as described in the in vitro experiments, except that each pulse was preceded by a prepulse of $3 \mathrm{sec}-$ onds at $-120 \mathrm{mV}$ to promote recovery of every $\mathrm{Na}_{v} \mathrm{~s}$ isoform. 
Pharmacological separation of $\mathrm{Na}_{v} 1.7, \mathrm{Na}_{v} 1.8$, and $r$ TTXs sodium currents. $\mathrm{Na}_{\mathrm{v}}$ total current-voltage (I-V), $\mathrm{Na}_{\mathrm{v}}$ total SSI, and $\mathrm{Na}_{\mathrm{v}}$ total RFI curves were obtained as mentioned above for the total $\mathrm{Na}_{\mathrm{v}}$ isoform component present in DRG neurons. ProTxII (5 nM; provided by B. Priest, Merck Serono), a selective blocker of $\mathrm{Na}_{\mathrm{v}} 1.7$, was then perfused, and a test pulse at $0 \mathrm{mM}$ was performed until the diminution of peak amplitude reached its steady state (toxin maximal effect). A 5-nM concentration of the toxin would block over $90 \%$ of $\mathrm{Na}_{\mathrm{v}} 1.7$ and less than $10 \%$ of the other isoforms (26). $\mathrm{Na}_{\mathrm{v}}$ total $^{\text {ProTxII }} \mathrm{I}-\mathrm{V}, \mathrm{Na}_{\mathrm{v}}$ total ${ }^{\text {ProTxII }} \mathrm{SSI}$, and $\mathrm{Na}_{\mathrm{v}}$ total $^{\text {ProTxII }}$ RFI were then recorded. Subtracting the total curves for $\mathrm{Na}_{\mathrm{v}}$ total I-V, $\mathrm{Na}_{v}$ total SSI, and $\mathrm{Na}_{v}$ total RFI from those of $\mathrm{Na}_{v}$ total ${ }^{\text {ProTxII }} \mathrm{I}-\mathrm{V}, \mathrm{Na}_{\mathrm{v}}$ total ${ }^{\text {ProTxII }}$ SSI, and $\mathrm{Na}_{v}$ total ${ }^{\text {ProTxII }} \mathrm{RFI}$ allowed us to measure $\mathrm{Na}_{v} 1.7$ I-V, $\mathrm{Na}_{v} 1.7$ SSI, and $\mathrm{Na}_{v} 1.7$ RFI. Finally, TTX $(300 \mathrm{mM})$ was added to isolate the $\mathrm{Na}_{\mathrm{v}} 1.8 \mathrm{I}-\mathrm{V}, \mathrm{Na}_{\mathrm{v}} 1.8 \mathrm{SSI}$, and $\mathrm{Na}_{\mathrm{v}} 1.8 \mathrm{RFI}$ curves. Subtracting the $\mathrm{Na}_{v} 1.8 \mathrm{I}-\mathrm{V}, \mathrm{Na}_{\mathrm{v}} 1.8 \mathrm{SSI}$, and $\mathrm{Na}_{\mathrm{v}} 1.8$ RFI curves from those of $\mathrm{Na}_{\mathrm{v}}$ total ${ }^{\text {ProTxII }}$ I-V, $\mathrm{Na}_{v}$ total $^{\text {ProTxII }}$ SSI, and $\mathrm{Na}_{\mathrm{v}}$ total ${ }^{\text {ProTxII }}$ RFI allowed us to record $\mathrm{Na}_{v} \mathrm{rTTX}$ I-V, $\mathrm{Na}_{\mathrm{v}}$ rTTXs SSI, and $\mathrm{Na}_{\mathrm{v}} \mathrm{rTTXs}$ RFI, representing the remainder of the TTX-sensitive current. For examples of this protocol for I-V curves, see Figure 3A.

\section{Statistics}

For in vitro experiments (current densities, biophysical properties, and protein quantification), data were analyzed using an unpaired, 2-tailed Student's $t$ test when 2 groups were compared, or 1-way ANOVA for multiple group comparisons. For ex vivo recordings (current densities and biophysical properties) and behavioral pain tests, normality was tested with a D'Agostino-Pearson omnibus test to determine whether parametrical (Student's $t$ ) or nonparametrical (Mann-Whitney $U$ ) tests would be used when 2 groups were compared. The same normality test was performed for multiple group comparisons to determine whether a regular 1-way ANOVA and post-hoc Bonferroni's tests, or the nonparametric equivalence test (Kruskal-Wallis and Dunn's post tests) would be performed. For behavioral pain time courses (von Frey filaments, formalin), 2-way ANOVA with repeated measures were performed. The statistical tests used are described in each figure legend. A $P$ value less than 0.05 was considered significant.

\section{Study approval}

All experimental procedures were approved by the Committee on Animal Experimentation of the Canton de Vaud, Switzerland, in accordance with the Swiss Federal Laws on Animal Welfare and the guidelines of the
International Association for the Study of Pain (Zimmermann, 1983). Animals were housed under a 12-hour light/12-hour dark cycle and had free access to food and water.

\section{Acknowledgments}

We thank O. Staub (Lausanne University) for providing NEDD42 purified antibody and the Nedd $4 L^{f l / f l}$ mouse line; R. Kuner (Heidelberg University) for providing the SNS-Cre mouse line; S. Tate and V. Morisset (Convergence Pharmaceuticals) for providing $\mathrm{Na}_{\mathrm{v}} 1.7$ cDNA cloned into pCIN5h and HEK293 cells stably expressing $\mathrm{Na}_{\mathrm{v}} 1.7$; and B. Priest (Merck Serono) for providing ProTxII. The monoclonal antibody N68/3 (anti-Na 1.7 ) was developed by and/or obtained from the UC Davis/NIH NeuroMab Facility, supported by an NIH grant (U24NS050606) and maintained by the Department of Neurobiology, Physiology and Behavior, College of Biological Sciences, University of California, Davis. We thank P. Aebischer (EPFL) for all the work performed in his laboratory and for his scientific advice. We thank M.R. Suter (CHUV and University of Lausanne), R.R. Ji (Duke University), C.J. Woolf (F.M. Kirby Neurobiology Center, Children's Hospital Boston and Harvard Medical School), and A. Felley (La Tour-dePeilz, Switzerland) for comments on the manuscript. This study was supported by grants from the Swiss National Science Foundation (31003A-124996 to I. Decosterd and 310030B-135693 to H. Abriel), the Synapsis Foundation (to I. Decosterd and H. Abriel), the European Society of Anesthesiology (to I. Decosterd), and the Lemanic Neuroscience Doctoral School PhD Fellowship (to C.J. Laedermann). The contribution of B. Gavillet to the preliminary experiments is acknowledged. We would also like to thank C. Kern (CHUV and University of Lausanne) for his support.

Received for publication January 24, 2013, and accepted in revised form April 19, 2013.

Address correspondence to: Hugues Abriel, Department of Clinical Research, University of Bern, Murtenstrasse 35, 3010 Bern, Switzerland. Phone: 41.31.6320928; Fax: 41.31.6320946; E-mail: Hugues. Abriel@dkf.unibe.ch. Or to: Isabelle Decosterd, Pain Center, University Hospital Center (CHUV) and University of Lausanne, Bugnon 46, 1011 Lausanne, Switzerland. Phone: 41.21.3142040; Fax: 41.21.214 3044; E-mail: Isabelle.Decosterd@chuv.ch.
1. Bouhassira D, Lanteri-Minet M, Attal N, Laurent $B$, Touboul C. Prevalence of chronic pain with neuropathic characteristics in the general population. Pain. 2008;136(3):380-387.

2. Amir R, Michaelis M, Devor M. Membrane potential oscillations in dorsal root ganglion neurons: role in normal electrogenesis and neuropathic pain. J Neurosci. 1999;19(19):8589-8596.

3. Nystrom B, Hagbarth KE. Microelectrode recordings from transected nerves in amputees with phantom limb pain. Neurosci Lett. 1981;27(2):211-216.

4. Costigan M, Scholz J, Woolf CJ. Neuropathic pain: a maladaptive response of the nervous system to damage. Annu Rev Neurosci. 2009;32(1):1-32.

5 . Brackenbury WJ, Isom LL. Na channel $\beta$ subunits: overachievers of the ion channel family. Front Pharmacol. 2011;2:53.

6. Payandeh J, Scheuer T, Zheng N, Catterall WA. The crystal structure of a voltage-gated sodium channel. Nature. 2011;475(7356):353-358.

t7. Ho C, O'Leary ME. Single-cell analysis of sodium channel expression in dorsal root ganglion neurons. Mol Cell Neurosci. 2011;46(1):159-166.
8. Fukuoka T, Kobayashi K, Yamanaka H, Obata K, Dai Y, Noguchi K. Comparative study of the distribution of the alpha-subunits of voltage-gated sodium channels in normal and axotomized rat dorsal root ganglion neurons. J Comp Neurol. 2008;510(2):188-206.

9. Cox JJ, et al. An SCN9A channelopathy causes congenital inability to experience pain. Nature. 2006;444(7121):894-898.

10. Fertleman CR, et al. SCN9A mutations in paroxysmal extreme pain disorder: allelic variants underlie distinct channel defects and phenotypes. Neuron. 2006;52(5):767-774.

11. Reimann F, et al. Pain perception is altered by a nucleotide polymorphism in SCN9A. Proc Natl Acad Sci U S A. 2010;107(11):5148-5153.

12. Faber CG, et al. Gain of function Nav1.7 mutations in idiopathic small fiber neuropathy. Ann Neurol. 2012;71(1):26-39.

13. Faber CG, et al. Gain-of-function Nav1.8 mutations in painful neuropathy. Proc Natl Acad SciUS A. 2012;109(47):19444-19449.

14. Gold MS, et al. Redistribution of NaV1.8 in unin- jured axons enables neuropathic pain. J Neurosci. 2003;23(1):158-166.

15. Luo S, Perry G, Levinson SR, Henry M. Nav1.7 expression is increased in painful human dental pulp. Mol Pain. 2008;4(1):16.

16. Persson AK, Gasser A, Black JA, Waxman SG. NaV1.7 accumulates and co-localizes with phosphorylated ERK1/2 within transected axons in early experimental neuromas. Exp Neurol. 2011;230(2):273-279.

17. Liu M, Wood JN. The roles of sodium channels in nociception: implications for mechanisms of neuropathic pain. Pain Med. 2011;12:S93-99.

18. Akopian AN, et al. The tetrodotoxin-resistant sodium channel SNS has a specialized function in pain pathways. Nat Neurosci. 1999;2(6):541-548.

19. Nassar MA, et al. Nociceptor-specific gene deletion reveals a major role for Nav1.7 (PN1) in acute and inflammatory pain. Proc Natl Acad Sci U S A. 2004;101(34):12706-12711.

20. Nassar MA, Levato A, Stirling LC, Wood JN. Neuropathic pain develops normally in mice lacking both Nav1.7 and Nav1.8. Mol Pain. 2005;1:24. 
21. Abriel H, Staub O. Ubiquitylation of ion channels. Physiology (Bethesda). 2005;20(6):398-407.

22. Abriel H, et al. Defective regulation of the epithelial $\mathrm{Na}^{+}$channel by Nedd4 in Liddle's syndrome. J Clin Invest. 1999;103(5):667-673.

23. van Bemmelen MX, et al. Cardiac voltage-gated sodium channel Nav1.5 is regulated by Nedd42 mediated ubiquitination. Circ Res. 2004; 95(3):284-291.

24. Fotia AB, Ekberg J, Adams DJ, Cook DI, Poronnik P, Kumar S. Regulation of neuronal voltagegated sodium channels by the ubiquitin-protein ligases Nedd4 and Nedd4-2. J Biol Chem. 2004;279(28):28930-28935.

25. Cachemaille M, Laedermann CJ, Pertin M, Abriel $\mathrm{H}$, Gosselin RD, Decosterd I. Neuronal expression of the ubiquitin ligase Nedd4-2 in rat dorsal root ganglia: Modulation in the spared nerve injury model of neuropathic pain. Neuroscience. 2012;227(0):370-380.

26. Schmalhofer WA, et al. ProTx-II, a selective inhibitor of NaV1.7 sodium channels, blocks action potential propagation in nociceptors. Mol Pharmacol. 2008;74(5):1476-1484.

27. Lopez-Santiago LF, et al. Sodium channel beta2 subunits regulate tetrodotoxin-sensitive sodium channels in small dorsal root ganglion neurons and modulate the response to pain. $J$ Neurosci. 2006;26(30):7984-7994.

28. Berta T, Poirot O, Pertin M, Ji RR, Kellenberger $\mathrm{S}$, Decosterd I. Transcriptional and functional profiles of voltage-gated $\mathrm{Na}^{+}$) channels in injured and non-injured DRG neurons in the SNI model of neuropathic pain. Mol Cell Neurosci. 2008;37(2):196-208.

29. Cummins TR, Waxman SG. Downregulation of tetrodotoxin-resistant sodium currents and upregulation of a rapidly repriming tetrodotoxin-sensitive sodium current in small spinal sensory neurons after nerve injury. J Neurosci.
1997;17(10):3503-3514.

30. Shi PP, et al. Salt-sensitive hypertension and cardiac hypertrophy in mice deficient in the ubiquitin ligase Nedd4-2. Am J Physiol Renal Physiol. 2008;295(2):F462-F470.

31. Agarwal N, Offermanns S, Kuner R. Conditional gene deletion in primary nociceptive neurons of trigeminal ganglia and dorsal root ganglia. Genesis. 2004;38(3):122-129.

32. Liu Y, et al. VGLUT2-dependent glutamate release from nociceptors is required to sense pain and suppress itch. Neuron. 2010;68(3):543-556.

33. Stirling LC, et al. Nociceptor-specific gene deletion using heterozygous NaV1.8-Cre recombinase mice. Pain. 2005;113(1-2):27-36.

34. Towne C, Pertin M, Beggah AT, Aebischer P, Decosterd I. Recombinant adeno-associated virus serotype 6 (rAAV2/6)-mediated gene transfer to nociceptive neurons through different routes of delivery. Mol Pain. 2009;5(1):52.

35. Decosterd I, Woolf CJ. Spared nerve injury: an animal model of persistent peripheral neuropathic pain. Pain. 2000;87(2):149-158.

36. Schmidt J, Rossie S, Catterall WA. A large intracellular pool of inactive $\mathrm{Na}$ channel alpha subunits in developing rat brain. Proc Natl Acad Sci US A. 1985;82(14):4847-4851.

37. McCall WD, Tanner KD, Levine JD. Formalin induces biphasic activity in C-fibers in the rat. $\mathrm{New}$ rosci Lett. 1996;208(1):45-48.

38. Agarwal N, et al. Cannabinoids mediate analgesia largely via peripheral type 1 cannabinoid receptors in nociceptors. Nat Neurosci. 2007;10(7):870-879.

39. Shields SD, et al. Nav1.8 expression is not restricted to nociceptors in mouse peripheral nervous system. Pain. 2012;153(10):2017-2030.

40. Lai J, et al. Inhibition of neuropathic pain by decreased expression of the tetrodotoxin-resistant sodium channel, NaV1.8. Pain. 2002;95(1-2):143-152.

41. Choi JS, Waxman SG. Physiological interactions between Nav1.7 and Nav1.8 sodium channels: a computer simulation study. J Neurophysiol. 2011;106(6):3173-3184.

42. Huang Y, Liu X, Dong L, Liu Z, He X, Liu W. Development of viral vectors for gene therapy for chronic pain. Pain Res Treat. 2011;2011:968218.

43. Diamyd Inc. Registry and results database of clinical studies of human participants around the world. NIH Web site. http://clinicaltrials.gov/ct2/ show/NCT00804076. Updated Ocotober 3, 2012. Accessed May 6, 2013.

44. Diamyd Inc. Registery and results database of clinical studies of human participants around the world. NIH web site. http://clinicaltrials.gov/ct2/ show/NCT01291901. Updated October 3, 2012. Accessed May 6, 2013.

45. Bongiorno D, Schuetz F, Poronnik P, Adams DJ. Regulation of voltage-gated ion channels in excitable cells by the ubiquitin ligases Nedd 4 and Nedd4-2. Channels (Austin). 2011;5(1):79-88.

46. Moss A, et al. A role of the ubiquitin-proteasome system in neuropathic pain. J Neurosci. 2002;22(4):1363-1372.

47. Bierhaus A, et al. Methylglyoxal modification of Nav1.8 facilitates nociceptive neuron firing and causes hyperalgesia in diabetic neuropathy. Nat Med. 2012;18(6):926-933.

48. Costigan $\mathrm{M}$, et al. Replicate high-density rat genome oligonucleotide microarrays reveal hundreds of regulated genes in the dorsal root ganglion after peripheral nerve injury. BMC Neurosci. 2002;3(1):16.

49. Cummins TR, Rush AM, Estacion M, Dib-Hajj SD, Waxman SG. Voltage-clamp and current-clamp recordings from mammalian DRG neurons. Nat Protoc. 2009; 4(8):1103-1112.

50. Cummins TR, Dib-Hajj SD, Black JA, Akopian AN, Wood JN, Waxman SG. A novel persistent tetrodotoxin-resistant sodium current in SNS-null and wild-type small primary sensory neurons. J Neurosci. 1999;19(24):RC43. 